\title{
Drone Measurements of Surface-Based Winter Temperature Inversions in the High Arctic at Eureka
}

\author{
Alexey B. Tikhomirov ${ }^{1, *}$, Glen Lesins ${ }^{1}$, and James R. Drummond ${ }^{1}$ \\ ${ }^{1}$ Department of Physics and Atmospheric Science, Dalhousie University, PO Box 15000, Halifax, Nova Scotia, B3H 4R2, \\ Canada
}

Correspondence: Alexey B. Tikhomirov (alexey.tikhomirov@dal.ca)

\begin{abstract}
The absence of sunlight during the winter in the High Arctic results in a strong surface-based atmospheric temperature inversion especially during clear skies and light surface wind conditions. The inversion suppresses turbulent heat transfer between the ground and the boundary layer. As a result the difference between the surface air temperature, measured at a height of $2 \mathrm{~m}$, and the ground skin temperature can exceed several degrees Celsius. Such inversions occur very frequently in 5 polar regions and are of interest to understand the mechanisms responsible for surface-atmosphere heat, mass and momentum exchanges and are critical for satellite validation studies.

In this paper we present the results of operations of two commercial remotely piloted aircraft systems, or drones, at the Polar Environment Atmospheric Research Laboratory (PEARL), Eureka, Nunavut, Canada, at $80^{\circ} \mathrm{N}$ latitude. The drones are the Matrice 100 and M210-RTK quad-copters manufactured by DJI and were flown over Eureka during the February-March field campaigns in 2017 and 2020. They were equipped with a temperature measurement system built on a Raspberry Pi single-board computer, three platinum wire temperature sensors, GNSS receiver, and a pressure sensor.

We demonstrate that the drones can be effectively used in the High Arctic to measure vertical temperature profiles up to $60 \mathrm{~m}$ of the ground and sea ice surface. Our results indicate that the inversion lapse rates within $0-10 \mathrm{~m}$ altitude range above the ground can reach the values of $\sim 0.1-0.3^{\circ} \mathrm{C} / \mathrm{m}\left(\sim 100-300^{\circ} \mathrm{C} / \mathrm{km}\right)$. The results are in a good agreement with the coincident temperatures measured at 2, 6 and $10 \mathrm{~m}$ levels at the National Oceanic and Atmospheric Administration flux tower at PEARL. Above $10 \mathrm{~m}$ a weaker inversion with an order of magnitude smaller lapse rates is recorded by the drone. The inversion strength agrees well with one obtained from the radiosonde temperature measurements. Above the sea ice, drone temperature profiles are found to have an isothermal layer above a surface based layer of instability which is attributed to the sensible heat flux through the sea ice. With the drones we were able to evaluate the influence of local topography on the surface-based inversion structure above the ground and to measure extremely cold temperatures of air that can pool in topographic depressions. The unique technical challenges of conducting drone campaigns in the winter High Arctic are highlighted in the paper.
\end{abstract}

\section{Introduction}

Atmospheric temperature is one of the key parameters used to study climate. In-situ temperature measurements are conducted from the ground by means of different types of thermometers (Taalas, 2018) and from airborne and space platforms using 
various remote sensing techniques (Pavelsky et al., 2011; Soliman et al., 2012; Key et al., 2016; Dodd et al., 2019). Satellite temperature observations are especially valuable, since they provide global coverage reaching the areas where ground-based air temperature measurements are challenging due to a small number of monitoring sites in the areas (i.e. above ocean surface, in mountain ridges, in the Arctic or Antarctica).

The World Meteorological Organization (WMO) assess global temperature fields and temperature anomalies based on the measurements of air temperature at 1.25 to $2 \mathrm{~m}$ above the ground level on the land. These temperatures are referred to "surface" temperatures. Surface temperatures derived from remote sensing measurements are also used in the WMO assessments. However, they are obtained from so called "skin" temperatures, which are temperatures at the surface-air interface, since they are retrieved from radiometric measurements (Li et al., 2013).

In polar regions in the absence of sunlight strong surface-based temperature inversions (SBIs) occur frequently. The occurrence rate is $>70$ and $>90 \%$ of the time in the Arctic and Antarctica respectively during winter months (see Bradley et al. (1993); Walden et al. (1996); Hudson and Brandt (2005) and references therein). Due to terrestrial radiative cooling of the surface in clear sky conditions and suppressed turbulent heat transfer between the ground and the boundary layer under light wind conditions, the difference between surface and skin temperature can be significant. Based on temperature measurements conducted at the South Pole in the winter of 2001 it was found that "median difference between the temperatures at $2 \mathrm{~m}$ and the surface" could reach $1.3^{\circ} \mathrm{C}$ in winter in clear sky conditions, which is equal to a $650^{\circ} \mathrm{C} / \mathrm{km}$ inversion lapse rate (Hudson and Brandt, 2005). According to the observations the strongest temperature gradient is confined within a $0.2 \mathrm{~m}$ air layer above the surface where the temperature difference is equal to $0.8^{\circ} \mathrm{C}$ leading to a $4000^{\circ} \mathrm{C} / \mathrm{km}$ inversion lapse rate. This difference between $2 \mathrm{~m}$ surface temperature and skin temperature results in a negative bias in the surface temperature products obtained from the satellite measurements (see Adolph et al., 2018 and references therein). Between $2 \mathrm{~m}$ and $100 \mathrm{~m}$ the monthly mean temperature gradient varies within $111-128^{\circ} \mathrm{C} / \mathrm{km}$ in March-September as reported by Hudson and Brandt (2005) based on radiosonde (RS) data from South Pole covering 1994-2003.

According to Bradley et al. (1993) the mean rate of the temperature change within the inversion measured in DecemberMarch during 1967-1986 at the RS sites in the Canadian Arctic and Alaska is in the range of $15-23^{\circ} \mathrm{C} / \mathrm{km}$, which is much less than one measured in Antarctica. Walden et al. (1996) reported the multi-year monthly averaged inversion lapse rate for 0-250 $\mathrm{m}$ altitude as being between 12 and $18^{\circ} \mathrm{C} / \mathrm{km}$ in Barrow, Alaska (1953-1990) and between 20 and $24^{\circ} \mathrm{C} / \mathrm{km}$ in Eureka, Nunavut (1967-1990). Lesins et al. (2010) reported on a weakening of the winter inversion strength at Eureka from 1985 to 2007 using the station RS observations. Zhang et al. (2011) analysed a dataset covering 20 years (1990-2009) of RS observations from 39 Arctic and 6 Antarctic sites and compared it to a reanalysis dataset and to simulations from climate models to examine spatial and temporal variability of SBI including frequency of occurrence, depth and intensity and relationships among them. They found the strength, occurrence frequency and depth of the SBI are larger in winter and fall than in summer and spring and are positively correlated, both spatially and temporally. Also all three characteristics are in inverse relationship with surface temperature. Lesins et al. (2012), based on the data from 22 Canadian Arctic RS stations covering 1971 to 2010, suggested that a strong SBI plays an important role in Arctic amplification of climate change. Smith and Bonnaventure (2017) analysed air and ground temperature data collected at Alert, Nunavut, Canada and found the SBI occurrence may have an effect on the 
spatial variation in the High Arctic permafrost thermal state, specifically in the regions with thin snow cover. Pavelsky et al. (2011) showed a correlation between the inversion strength and annual sea ice concentration in the Arctic and Antarctica. After analysing data on the near-surface temperature inversions from the Atmospheric Infrared Sounder they suggested the inversion strength could be controlled by the ice concentration through modulation of the surface heat fluxes. Thus, monitoring and characterisation of SBI remains important in understanding its role in atmospheric processes and ocean-atmosphere interaction.

In recent years Remotely Piloted Aircraft Systems (RPAS), or drones, have become a commonplace in industry and science (Chabot and Bird, 2015; Kräuchi and Philipona, 2016; Cowley et al., 2017; Gaffey and Bhardwaj, 2020; Lampert et al., 2020a,b). There are two main drone types used in research: fixed-wing and multi-rotor. Both have certain advantages and limitations which affect the performance in specific situations. Fixed-wing drones are optimal for large area surveys where longer endurance, fast speed and hence larger spatial coverage are the most critical factors (Jouvet et al., 2019; Zappa et al., 2020). They can handle larger payload meaning that more and heavier sensors can be installed onboard. For these reasons they are widely used for meteorological and atmospheric science applications (Knuth and Cassano, 2014; Cassano et al., 2016; Bärfuss et al., 2018; Zappa et al., 2020) and glaciology (Jouvet et al., 2019).

On the other hand multi-rotor vehicles can hover in one spot, which is critical for photography surveys. Also their lower speeds and superior manoeuvrability means that flying in the rough topographic environment become less challenging (Shahmoradi et al., 2020). Multi-rotor RPASs are easier to operate and they do not require special equipment such as a catapult or a long runway for a launch. However shorter flight time and smaller payload capacity are significant drawbacks of the multi-rotor drones.

The application of multi-rotor RPAS to study temperature inversions up to $1000 \mathrm{~m}$ above the ground in urban areas in winter time has been reported by Mašić et al. (2019). These authors conducted observations in many different SBI scenarios at ambient temperatures falling below $-20^{\circ} \mathrm{C}$ in the context of local air pollution. They also highlighted the advantages of using drones in comparison with other techniques (RS, microwave radiometry, cable-car and ground-based measurements). Among those advantages are lower operation cost per single temperature profile, good control over the flight parameters, ability to measure temperature during both ascent and descent and finer vertical resolution. All of them are critical for SBI measurements.

In polar regions drones provide unique opportunities to conduct research due to their remote operation capabilities, mobility and relatively low cost in comparison with manned aircraft. However, the harsh environment of high latitudes including surface air temperatures below $-30^{\circ} \mathrm{C}$, close proximity to the Earth's magnetic pole, poor performance of Global Navigation Satellite System (GNSS) receivers and complete darkness during the polar night pose challenges for drone operations (Gustafsson and Bendz, 2018). Technical difficulties and examples of application of a $19 \mathrm{~kg}$ quad-copter custom built for polar missions to study atmospheric boundary layer at $79^{\circ} \mathrm{N}$ in Greenland and deployable from a research vessel has been recently reported by Lampert et al. (2020a). The authors measured vertical profiles of meteorological parameters within $1000 \mathrm{~m}$ altitude range at up to $8 \mathrm{~m} / \mathrm{s}$ drone ascent/descent speeds and provided detailed analyses of their findings and factors affecting the results such as the impact of rotor blades, turbulent fluctuations and heat produced by drone motors on temperature measurements. Also they highlighted that due to Earth's magnetic field anomalies and magnetic disturbances produced by the vessel, takeoff and 
landing had to be performed manually and certain adjustments had to be applied to the autopilot system to correct for this during operations.

Many research groups have developed RPASs on open-source platforms (Ebeid et al., 2017) and optimized them for specific applications (Roldán et al., 2015; Kräuchi and Philipona, 2016; Villa et al., 2016; Mašić et al., 2019; Jouvet et al., 2019; Lampert et al., 2020b), while others utilize "off-the-shelf" (Cowley et al., 2017; Burgués and Marco, 2020) or sophisticated commercial solutions (Knuth and Cassano, 2014; Cassano et al., 2016; Bärfuss et al., 2018; Zappa et al., 2020). Although, both approaches have their merits and a variety of successful examples can be found in the literature (Gaffey and Bhardwaj, 2020), many factors like technology availability and flexibility, equipment and maintenance cost have to be taken into consideration during project planning.

As drone technology emerged and became more accessible recently, we started to develop a concept to study SBI at the Polar Environment Atmospheric Research Laboratory (PEARL, Fogal et al., 2013) in Eureka, Nunavut, Canada, at $80^{\circ} \mathrm{N}$ latitude with RPAS in 2016. We were driven by the idea of using a commercial "turn-key" drone solution for our application. Keeping this in mind, the plan was to evaluate and learn whether an "off-the-shelf" drone can be economic, robust and reliable in the High Arctic environment, so the time and efforts spent on a development of a custom system can be saved.

The goal of this paper is to present the results of the first pilot studies of the temperature profiles within $60 \mathrm{~m}$ of the ground conducted in Eureka using a custom built temperature sensing system installed on a commercial multi-rotor RPAS.

To achieve the goal the following tasks have been accomplished.

Technical tasks:

- Two commercial quad-copters with different navigation systems were identified, acquired and flown in Eureka to demonstrate and evaluate the feasibility of conducting drone operations at $80^{\circ} \mathrm{N}$.

- A custom built temperature measurement system was installed and tested onboard the quad-copters to evaluate its potential in providing reliable temperature data.

- The quality of temperature measurements, conducted in field conditions, relative to sensor locations onboard the drone was examined using three identical temperature sensors.

Scientific tasks:

- The results of the drone SBI measurements were validated against the data from the flux tower, radiosondes and weather stations in Eureka.

- Drone vertical temperature profiles collected over flat terrain and in a gully in Eureka were examined to determine the role of local topography in the SBI shaping.

- Drone vertical temperature profiles collected over the sea ice were examined for the signs of the sensible heat flux through the sea ice. of conducting drone operations in the High Arctic in winter conditions. 


\section{Methods and instrumentation}

\subsection{Remotely piloted aircraft systems}

Two RPASs have been identified, acquired and tested to study SBI in the harsh environment of the High Arctic in Eureka. Both drones are commercially available quad-copters manufactured by DJI. Detailed specifications of the drones can be found on the DJI web page (DJI, a, DJI, b). The first drone, Matrice 100 (M100), is a development grade quad-copter with 650 mm diagonal wheelbase and $3.6 \mathrm{~kg}$ maximum takeoff weight. The drone can be powered either from a standard (TB47D, $4500 \mathrm{mAh}$ ) or extended (TB48D, $5700 \mathrm{mAh}$ ) capacity lithium polymer (LiPo) battery and can be configured to use a single battery or two in parallel. Depending on the configuration typical hovering time can vary between 19 and 40 min with 0.5-1.2 $\mathrm{kg}$ of payload. For navigation the drone relies on its Inertial Measurement Unit (IMU), compass and GNSS. According to specification its hovering accuracy is better than $0.5 \mathrm{~m}$ and $2.5 \mathrm{~m}$ in vertical and horizontal directions respectively.

The second drone, Matrice 210-RTK (M210-RTK), is an industrial grade quad-copter. It has $643 \mathrm{~mm}$ diagonal wheel base and $6.14 \mathrm{~kg}$ maximum takeoff weight. It employs a pair of standard (TB50, 4280 mAh) or extended (TB55, 7660 mAh) capacity batteries. Both TB50 and TB55 battery types are equipped with heaters. The heater turns itself on if the battery temperature falls below $15^{\circ} \mathrm{C}$. Maximum drone flight time varies between 13 and $32 \mathrm{~min}$ depending on the payload weight and type of the batteries installed. Approximate maximum payload is $1.7 \mathrm{~kg}$ with a set of standard batteries and $1 \mathrm{~kg}$ with extended capacity batteries. The M210-RTK differs from the M100 by its advanced navigation system which employs Real-Time Kinematic (RTK), a differential GNSS technique, that can provide high positioning performance when used together with a base station. According to specification $0.1 \mathrm{~m}$ hovering accuracy in both vertical and horizontal directions can be reached by utilizing the drone together with DJI D-RTK ground system kit (RTK mode). The drone is also equipped with an obstacle avoidance system to make the flights safer. The air-frames of both drones are made with carbon fibre and aluminum, which makes them suitable for low temperatures. The drones and their payload configuration are shown in Figures 1 and 2. Payload details are discussed further in the paper.

\subsection{Onboard data collection system and sensors}

To record the ambient air temperature during the flights three identical platinum wire Resistance Temperature Detector (RTD) sensors were installed aboard the drones. The RTD sensors are $1 \mathrm{~mm}$ in diameter and $15 \mathrm{~mm}$ long ceramic wire-wound elements (1PT100KN1510, Omega Engineering, Inc.). Each RTD element is connected to its own MAX31865PMB1 peripheral module (Maxim Integrated Products, Inc., 2014). The modules employ the MAX31865 resistance-to-digital converter optimized for platinum RTDs. The converter has $0.031^{\circ} \mathrm{C}$ resolution and $0.5^{\circ} \mathrm{C}(0.05 \%$ of full scale $)$ total accuracy at $21 \mathrm{~ms}$ conversion time. The modules with RTD elements were housed in a $25 \mathrm{~mm}$ diameter and $75 \mathrm{~mm}$ long PVC tubes for protection. The first module was attached to the top side of the drone close to its center point (top RTD, see Figures 1 and 2). The second module was attached to the tip of a $\sim 60 \mathrm{~cm}$ long pole at the front side of the drone (pole RTD). This was done to minimize the influence of turbulent air flows produced by the drone's propellers on temperature measurements (Greene et al., 2018; Lampert et al., 


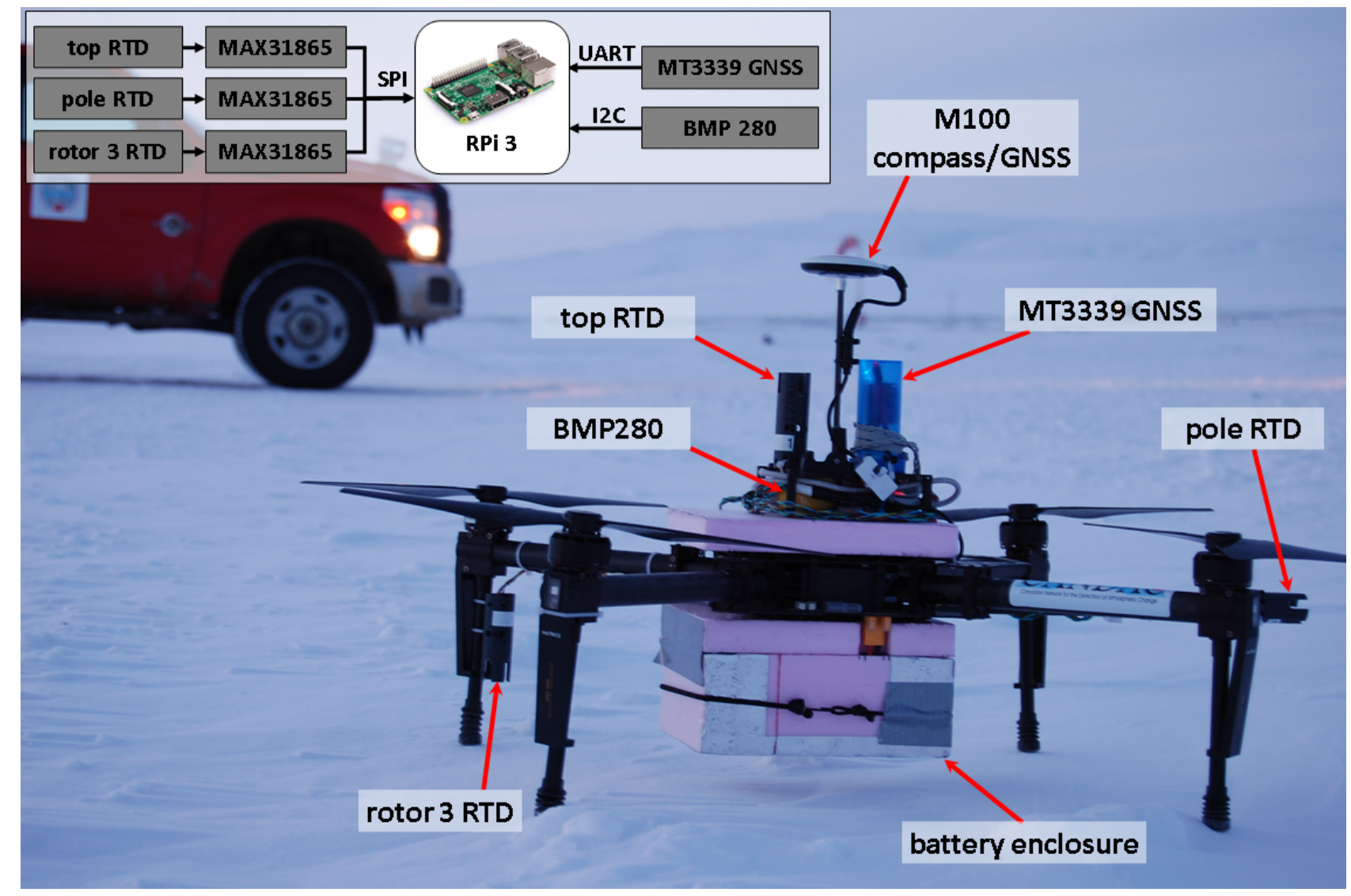

Figure 1. DJI M100 drone and its payload.

2020a). The third module was mounted under the left rear rotor (rotor 3 RTD). All three modules are connected to the onboard data collection system via a Serial Peripheral Interface (SPI).

To record the horizontal location of the drone a spare GNSS module is installed onboard. The module utilizes MediaTek Chipset MT3339 capable of up to $10 \mathrm{~Hz}$ data update rate. The module is connected to the onboard data collection system via UART interface.

To have an altitude reference a separate barometric altimeter is installed. The altimeter is a BMP280 digital pressure sensor (Bosch Sensortec, 2018). It is connected to the onboard data collection system via Inter-Integrated Circuit (I2C) interface. The accuracy of the altimeter is $\pm 0.5 \mathrm{~m}$. The altimeter was verified by comparing its pressure readings to simultaneous measurements taken with a Vaisala WXT-520 weather transmitter within the pressure range between 920 and 1002 mbar. The results showed good agreement between the two sensors.

The onboard data collection system is built on a Raspberry Pi (RPi) model 3 single-board computer with Raspbian operating system (The Raspberry Pi Foundation). Power to the RPi is provided from the drone's extended power port (output voltage range: $18-26 \mathrm{~V}$ ) via $5 \mathrm{~V}$ universal battery eliminator circuit (UBEC) DC/DC step-down voltage converter. The acquisition code, 


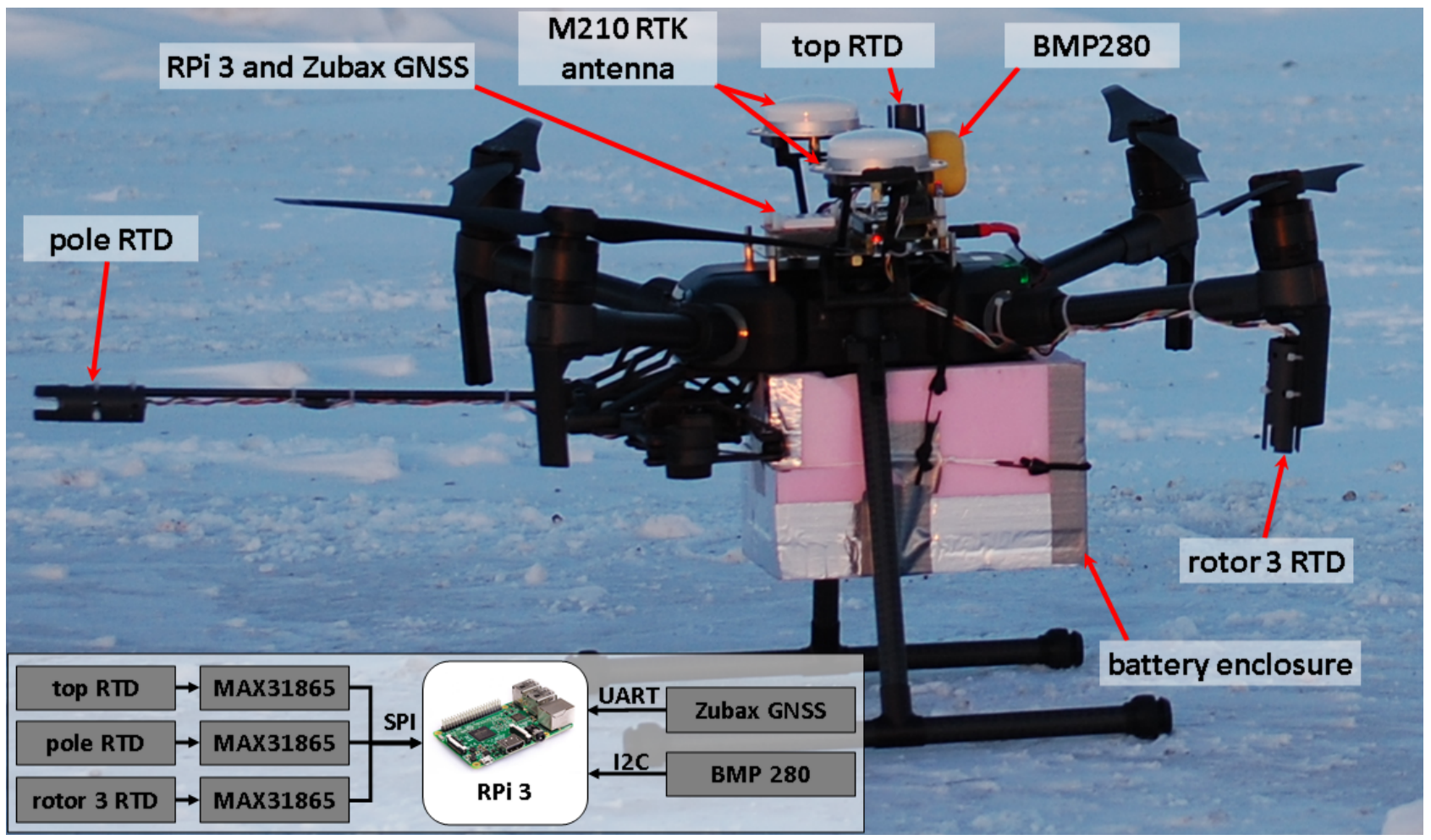

Figure 2. DJI M210-RTK drone and its payload.

written in Python, polls each sensor at a sampling frequency of $10 \mathrm{~Hz}$ and saves the acquired data in ASCII format to the RPi's microSD card for post processing. Total weight of the data collection system together with the sensors is $<0.3 \mathrm{~kg}$.

\subsection{Site description}

Drone flights were conducted in Eureka, a small research base located on Ellesmere Island, Nunavut, Canada. The base consists of three main areas: the Environment and Climate Change Canada (ECCC) Weather Station (WS) - a facility complex built at the northern side of Slidre Fjord, on Fosheim Peninsula of the island $\left(79.9890^{\circ} \mathrm{N}, 85.9386^{\circ} \mathrm{W}, 10\right.$ m.a.s.l.), the Eureka Aerodrome (ICAO code: C-YEU, $79.9944^{\circ} \mathrm{N} 85.8119^{\circ} \mathrm{W}, 83$ m.a.s.1.) located $\sim 2.5 \mathrm{~km}$ east-north-east of the ECCC WS, and PEARL - an atmospheric research facility, which includes several laboratories at different locations within the vicinity of Eureka.

The region around Eureka is a polar desert with mean annual temperature about $-19^{\circ} \mathrm{C}$ and annual water equivalent precipitation of 70 millimeters (Bernard-Grand'Maison and Pollard, 2018). The region has very little snow cover during the winter period, i.e. 20-30 cm deep snow drifts in the hollows and almost no snow on small hummocks.

In Eureka the standardized meteorological observations are conducted at two observing stations. The first station is a WMO certified site (Eureka C, WMO ID: 71613) located $\sim 100$ m east by north of the ECCC WS main building (see Figure 3). The 


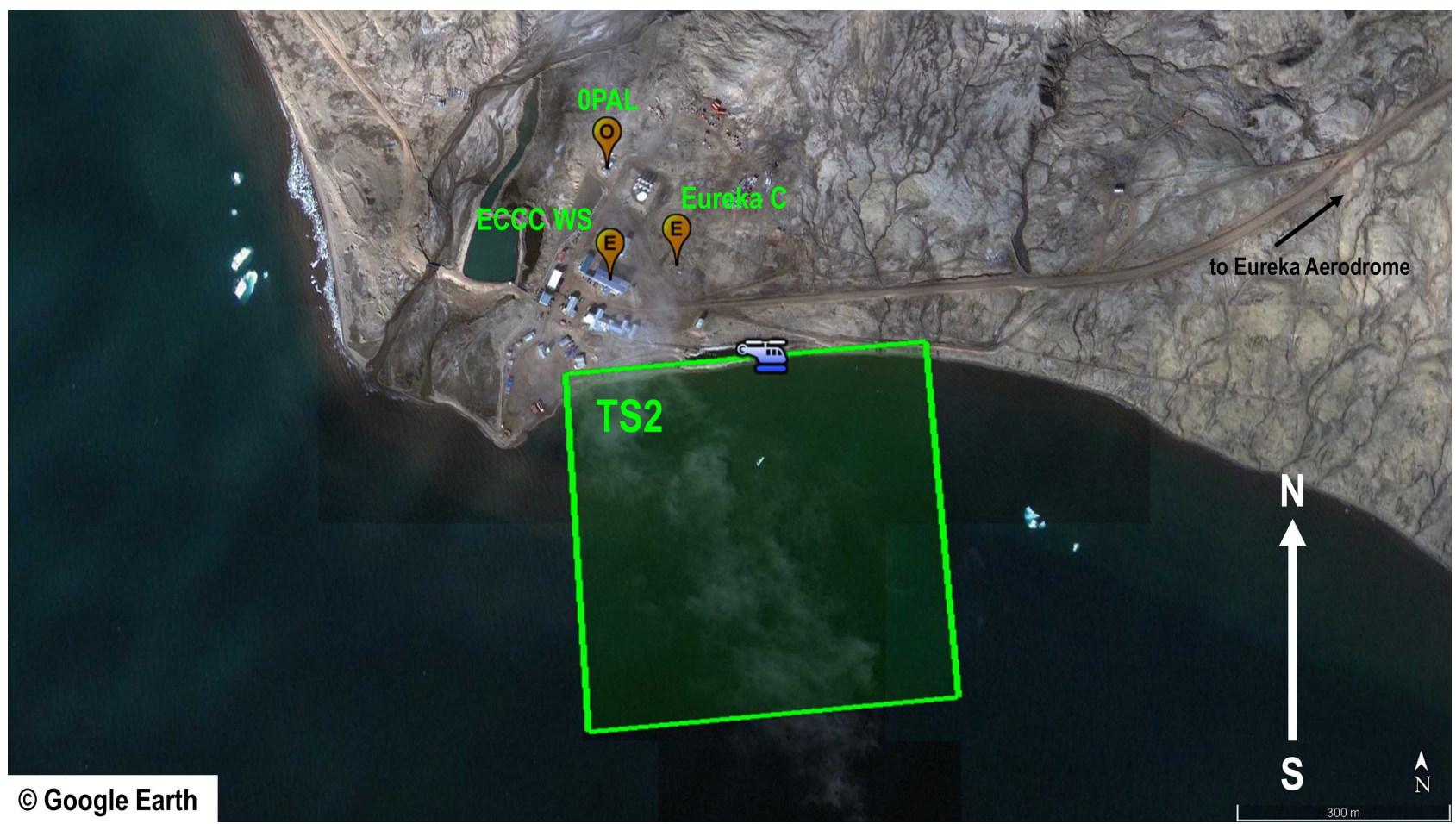

Figure 3. Flight region on Slidre Fjord near Eureka Weather Station.

second station is a NAV Canada automatic meteorological station (Eureka A, WMO ID: 71917) located nearby the Eureka Aerodrome runway (see Figure 4). It monitors the weather conditions specific to the aerodrome. Both stations provide hourly weather reports. Also, radiosondes are launched routinely twice a day at 11:15 and 23:15 UTC from the ECCC WS all year round. Radiosondes provide vertical profiles of pressure, temperature, relative humidity, wind speed and direction from the ground up to $30-35 \mathrm{~km}$.

Additionally, meteorological measurements are conducted at PEARL. An automatic weather transmitter (Vaisala WXT-510) is installed at the Zero Altitude PEARL Auxiliary Laboratory (OPAL, $79.9905^{\circ} \mathrm{N}, 85.9388^{\circ} \mathrm{W}$ ), located $\sim 160 \mathrm{~m}$ north of the ECCC WS main building. The National Oceanic and Atmospheric Administration (NOAA) Flux Tower (FT), a $2 \mathrm{~m}$ by $2 \mathrm{~m}$ wide and $10 \mathrm{~m}$ tall tower, is installed approximately $250 \mathrm{~m}$ north-north-east of the East end of the aerodrome runway. Geographical coordinates of the FT are: $79.9955^{\circ} \mathrm{N}, 85.7716^{\circ} \mathrm{W}$ (see Figure 4). The FT is equipped with temperature sensors (at 2, 6 and $10 \mathrm{~m}$ levels relative to the FT base), anemometers, precipitation sensors, barometer and other meteorological and scientific instruments. Detailed descriptions of the FT instrumentation suite and related measurements made at the site can be found in Grachev et al., 2018 and references therein. Both the weather transmitter at OPAL and the sensors at the FT provide data on the weather conditions at their locations with one-minute resolution.

Drone temperature measurements were performed during multiple flights at two test sites. The first test site (TS1, marked in green shading in Figure 4) is an inverted L-shape area of $1 \mathrm{~km}$ by $1 \mathrm{~km}$ near the East end of the runway of Eureka Aerodrome. 


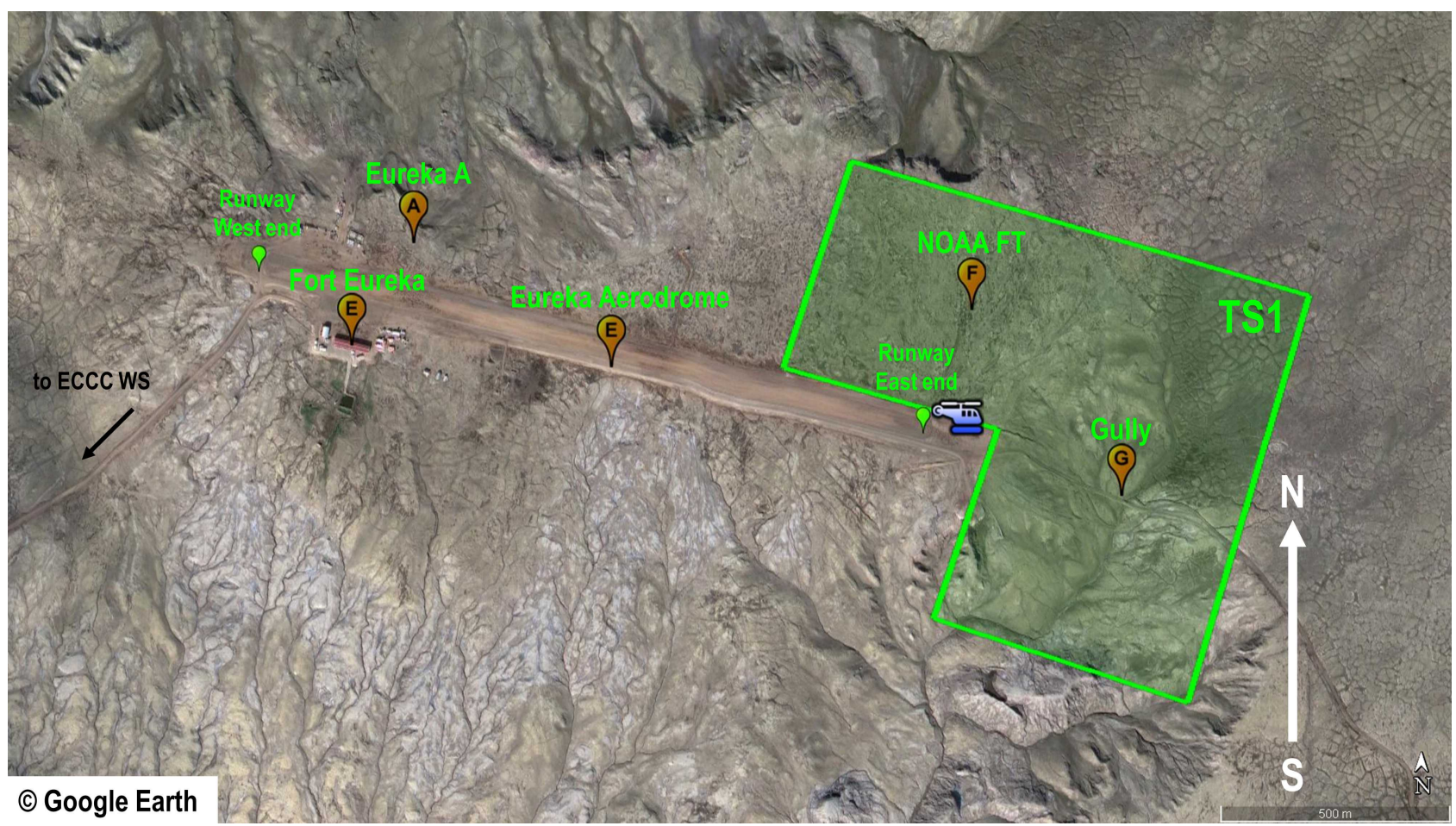

Figure 4. Flight region near the Eureka Aerodrome and NOAA Flux Tower.

The site was chosen specifically to study SBI over land due to a favourable combination of a flat terrain and local topographic features. It is a thermokarst landscape of ice-rich permafrost tundra with a flat plateau located at the northern side of the runway and surrounded by gullies (Pollard, 2000). TS1 region is located in close proximity to the Eureka A meteorological station and includes the NOAA FT.

The second site (TS2, marked in green shading in Figure 3) is a $0.5 \mathrm{~km}$ by $0.5 \mathrm{~km}$ area on the ice of the Slidre Fjord $\sim 200 \mathrm{~m}$ east-south-east of the ECCC WS and Eureka C meteorological station. The fjord is covered by ice between September and July with an ice thickness of about $0.5 \mathrm{~m}$ in October and reaching $2 \mathrm{~m}$ in May according to the ice surveys performed by ECCC staff at the WS. The ice is characterized by low snow drifts on its flat surface and no signs of ice breaking during the measurement period. This site was chosen to investigate the features of the SBI above the ice covered ocean.

The drone takeoff/landing locations for both sites are marked by a helicopter symbol in Figures 3 and 4 .

\subsection{Drone batteries in cold environment}

The cold and harsh environment of the High Arctic brings certain challenges to drone operations (see Ader and Axelsson, 2017; Kramar and Maatta, 2018; Lampert et al., 2020a and therein). Among these are very low ambient temperatures, complete

215 darkness during polar night, and navigation difficulties associated with close proximity to the the North Magnetic Pole and poor GNSS performance at high latitudes. 
According to specifications, certified operation temperatures are: -10 to $40^{\circ} \mathrm{C}$ for $\mathrm{M} 100$ and -20 to $50^{\circ} \mathrm{C}$ for M210-RTK. In the High Arctic typical winter ambient temperatures fall below $-30^{\circ} \mathrm{C}$. The main technical challenge associated with cold temperatures is poor performance of lithium batteries (Zhang et al., 2003). While the electronics and mechanics of the drones work well down to $-40^{\circ} \mathrm{C}$, the efficiency of the batteries drops drastically below $-20^{\circ} \mathrm{C}$, which affects the duration of the flight. According to Pesaran et al., 2013 the optimal range of operating temperatures for lithium batteries spans between 15 and $35^{\circ} \mathrm{C}$. We observed that while the drone's batteries generate internal heat during flight, this cannot keep the batteries within the optimal operation temperature range at below $-20^{\circ} \mathrm{C}$ ambient air temperatures, even in the case of the M210-RTK which is equipped with battery heaters. To solve this an enclosure made of $25 \mathrm{~mm}$ thick extruded polystyrene rigid insulation sheet ( $\mathrm{R}=5$ per $25 \mathrm{~mm}$ of thickness) was built around the battery compartments of both drones (see Figures 1 and 2 ). It allows easy installation and removal of the batteries and keeps them at optimal operational temperature around $30^{\circ} \mathrm{C}$ during the operation.

\section{$2.5 \quad$ Flight strategy and operation challenges}

All drone operations reported here were performed within the framework of the research activities conducted at PEARL and in accordance with Canadian Aviation Regulations for RPAS. Before June 1, 2019 the flights were conducted under Special Operation Flight Certificate. After June 1, 2019 the flights were conducted according to the updated Part IX of the Canadian Aviation Regulations. Special procedures were established for operations in the vicinity of Eureka Aerodrome.

Initial flight strategy consisted of several autonomous or manual flights per day at various locations within TS1 and TS2 regions in the line-of-sight conditions with periodic ascents up to $90 \mathrm{~m}$ altitude followed by descents.

Every time before conducting a flight the weather conditions were checked to make sure they are favourable for SBI measurements: sky is clear, ambient temperature is below $-30^{\circ} \mathrm{C}$, and wind speed is below $5 \mathrm{~km} / \mathrm{h}$.

To address the issues associated with effects of cold weather on the pilot's performance all flight controls were conducted from a truck parked nearby the flight region. Also the pilot wore touchscreen friendly electrically heated gloves to be able to navigate the drone using a tablet and to keep their hands warm.

Potential challenges associated with propeller icing and darkness during the operations did not occur. All the flights were performed below $-30^{\circ} \mathrm{C}$ ambient temperature and at around $70 \%$ relative humidity. In such conditions the air was very dry and we have not observed any indications of icing on the propellers nor on the drone airframe during the flights. Since the operations were conducted at the end of February to the beginning of March there was enough sunlight during the day to conduct the flights in well illuminated conditions.

The challenges and solutions related to drone navigation are discussed in subsequent sections of the paper.

\section{Results and Discussion}

\subsection{M100 drone}




\subsubsection{M100 first test flights and navigation challenges}

Our first tests with M100 in Eureka were conducted in February 2017. The purpose of the tests was to evaluate the possibility of autonomous flights and demonstrate the capability of the sensors and data collection system to provide reliable data at ambient temperatures below $-30^{\circ} \mathrm{C}$ in the High Arctic.

The drone was programmed to perform autonomous flights according to a predefined way-point pattern at constant altitude above the surface within TS1 region in the so-called positioning mode (P-mode). In P-mode the drone utilizes onboard GNSS receiver and barometric altimeter to maintain its horizontal and vertical position. Bearing information is taken from the onboard compass. Unfortunately in Eureka M100 autonomous flights were unsuccessful. The drone failed to maintain constant altitude and systematically climbed up during the course of the flight while the telemetry indicated that the flight was performed at fixed altitude. By the end of each autonomous flight the drone could gain an extra 30-50 m of altitude relative to predefined settings. Also there were many cases when the drone lost its bearing and flew in circular patterns.

Similar tests conducted in Halifax, NS, Canada, located at a more southerly latitude $\left(44.6^{\circ} \mathrm{N}, 63.6^{\circ} \mathrm{W}\right)$, did not have such problems and drone performance was satisfactory during those flights. We associate these navigation issues with a failure of M100 navigation system to lock on the GNSS signal and poor performance of the internal compass and barometric altimeter in the High Arctic latitudes and at low temperatures.

Due to this all further tests with M100 in Eureka were performed in so-called attitude mode (A-mode) in which the GNSS signal is not used for positioning, and the drone utilizes its barometric altimeter to maintain altitude. Since altitude maintenance was problematic the flights were conducted in true manual mode based on visual observations.

\subsubsection{M100 temperature measurements}

During further flights we tested the performance of the sensors and data collection system. The drone was flown in a pattern with periodic ascents and descents to measure vertical temperature profiles. Each temperature profile consisted of temperature measurements conducted on a single ascent followed by single descent at a fixed location within the TS1 region. An example of the temperature profile measured above packed snow at the East end of the runway $250 \mathrm{~m}$ south of the FT on February 28, 2017 is shown in Figure 5 (Flight 1, Profile 1). The altitude scale is taken relative to the altitude of the takeoff/landing pad which is at the same level as the FT base. Temperature variations measured at the FT at 2,6 and $10 \mathrm{~m}$ above the surface during the time frame of the drone flights are shown in thick lines in Figure 5. Temperature profiles from the RS launched from the ECCC WS at 11:15 and 23:15 UTC and corrected for the altitude difference between the ECCC WS and the TS1 takeoff/landing pad elevations are also shown in Figure 5 for reference. It can be seen that a strong temperature inversion is present in the first $10 \mathrm{~m}$ above the ground with an inversion lapse rate close to $\sim 0.3^{\circ} \mathrm{C} / \mathrm{m}$ (equal to $300^{\circ} \mathrm{C} / \mathrm{km}$, dotted line in Figure 5). The inversion becomes weaker above $10 \mathrm{~m}$ with an inversion lapse rate close to $\sim 0.04^{\circ} \mathrm{C} / \mathrm{m}$ (equal to $40^{\circ} \mathrm{C} / \mathrm{km}$, dashed line in Figure 5).

Some difference is observed in the temperature measurements carried out on the drone's ascent and descent. This is associated with the response time of the temperature sensors, vertical speed of the drone and air mixing produced by the drone propellers. During the tests the ascent/descent vertical speed of the drone was 1-1.2 $\mathrm{m} / \mathrm{s}$. This vertical speed results in hys- 


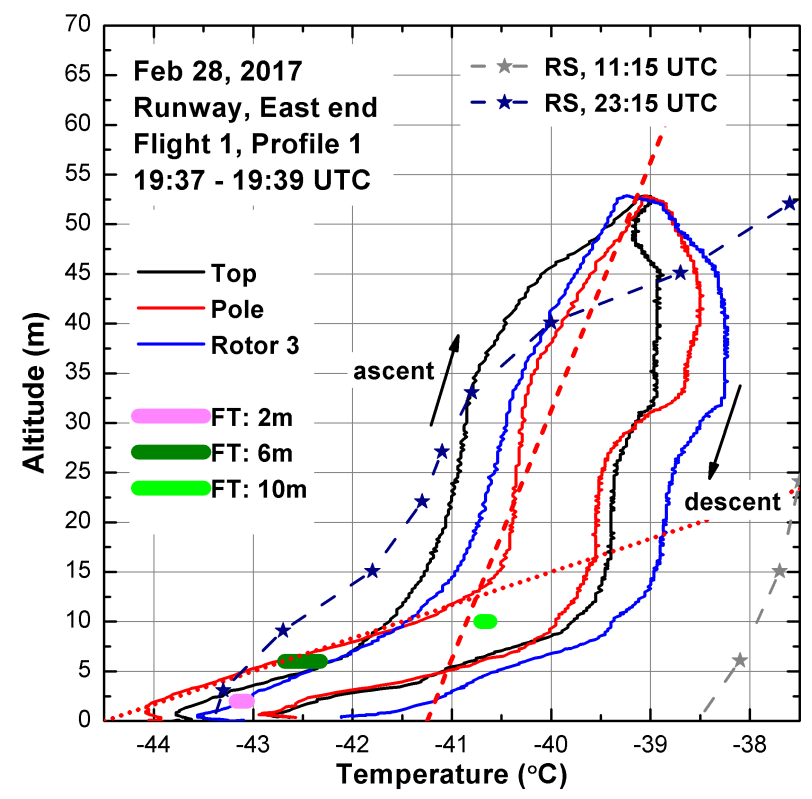

Figure 5. An example of the vertical temperature profiles measured by M100 near the takeoff/landing pad $250 \mathrm{~m}$ south of the FT between 19:37 and 19:39 UTC on February 28, 2017. Dotted line represents $0.3^{\circ} \mathrm{C} / \mathrm{m}\left(300^{\circ} \mathrm{C} / \mathrm{km}\right)$ inversion lapse rate. Dashed line represents $0.04^{\circ} \mathrm{C} / \mathrm{m}\left(40^{\circ} \mathrm{C} / \mathrm{km}\right)$ inversion lapse rate. Thick solid lines represent temperature variations as measured by the FT at 2,6 and $10 \mathrm{~m}$ altitudes between 19:37 and 19:39 UTC.

teresis loops in the measured temperature vertical profiles when the response time of the sensors is not optimal (Mašić et al., 2019). Slight differences in the temperature readings from the three RTD sensors can be explained by the different locations of the sensors on the drone frame. The readings from the RTD attached under the left rear rotor (rotor 3 RTD) exhibit a systematic bias relative to the readings from the two other sensors (top and pole, see Figure 1 for locations of the RTDs on the drone frame). The bias is more visible during the drone's descent when in the presence of a strong temperature inversion the propulsion system pushes warmer air from above the drone downward and mixes it with colder air under the drone.

The results of the tests conducted in February 2017 showed that the drone was able to provide reliable data at ambient temperatures below $-40^{\circ} \mathrm{C}$. The temperature profiles obtained from the drone are in agreement with the data from the FT. Comparisons with RS data indicated some variations in the absolute temperatures and the lapse rates obtained from the instruments. While in Figure 5 the drone temperature profile has reasonably good match with the 23:15 UTC RS profile, a several degrees positive or negative bias can be observed between the profiles from day to day. First of all, this could be due to the time difference between the drone flights and RS launches, which were several hours apart. Secondly, the RS are launched from the ECCC WS. The TS1 region and the ECCC WS have $\sim 3.3 \mathrm{~km}$ horizontal separation from each other and are sitting at different elevations above the mean sea level. When the RS reaches the elevation of the TS1, it is $\sim 73 \mathrm{~m}$ above the launch site ground. Due to this and local topographic features, the SBI sensed by the RS could differ from the SBI sensed by the drone. 


\subsection{M210-RTK drone}

\subsubsection{M210-RTK flight procedure}

In 2018 the M100 was replaced by the M210-RTK. The main purpose of the replacement was to improve the positioning accuracy and enhance the stability during autonomous flights. Also the original onboard data collection GNSS receiver (MediaTek, MT3339) was replaced by a more advanced one built on u-blox MAX-M8Q concurrent GNSS engine (Zubax Robotics, 2019). It obtains position information from GPS, GLONASS and Galileo constellations simultaneously at up to $15 \mathrm{~Hz}$ update rate. Additionally the temperature sensor attached to the pole was equipped with a small fan which provided aspiration of the RTD element by forced air flow at $\sim 1 \mathrm{~m} / \mathrm{s}$ speed to improve its response time.

Due to some technical problems with M210-RTK initial firmware and a few hardware failures, full scale operations in Eureka resumed only in 2020. Temperature measurements were conducted at both TS1 and TS2 regions. Typical flight time varied between 22 and 29 min per set of two TB55 batteries. Since we had two sets available and it usually took 4 hours to recharge them with a standard charging hub (DJI IN2CH), M210-RTK temperature measurements were limited to two flights per day.

All the measurements were performed at low ascent/descent speeds $(<0.1 \mathrm{~m} / \mathrm{s})$ to minimize the effect of the RTD response time on the results. The obstacle avoidance system of the drone was disabled during all flights. Table 1 summarizes the flights conducted between March 2 and 10, 2020 using the M210-RTK drone. The 19:00 UTC meteorological conditions are outlined in Table 2 for three locations: 1 - the ECCC WS (Eureka C), 2 - the NAV Canada meteorological station (Eureka A), and 3 the weather transmitter at OPAL (OPAL). Unfortunately, due to a hardware failure no meteorological data were available from FT for the time period covering M210-RTK flights.

On March 2 and 3 four preliminary flights were performed to test the drone and the flight procedure. The results of the preliminary flights showed that when the RPAS's navigation system failed to engage RTK mode, which happened sporadically, the drone performance was somewhat similar to one observed with M100. Main symptoms of the failure were circular shape flight tracks, fly away events and/or the inability of the drone to keep its altitude constant during the flight. Unfortunately, due to a "black box" type of the M210-RTK navigation system it was not possible to find a solution. During the test flights conducted in Halifax, the RPAS's navigation system managed to engage the RTK mode all the time and kept the positioning accuracy and stability of the drone within the specification. Additional tests showed that the drone provides equally good performance while flying either in RTK engaged or P-mode when RTK is intentionally disengaged.

Our measurement flights started on March 5. Between March 5 and 9 the flights were conducted in the TS1 region. Each operation day consisted of two types of flight. An example of flight trajectories for March 6 is shown in Figure 6. The first type was an autonomous flight with periodic ascents and descents from the East end of the runway towards the FT (flux tower flight, an example of the flight trajectory is marked in red in Figure 6). This type of flight was conducted to study the SBI and its temporal and spatial variability over a flat terrain. 
Table 1. M210-RTK flights in 2020

\begin{tabular}{|c|c|c|c|c|}
\hline Date & Takeoff time (UTC) & Landing time (UTC) & Flight duration (min) & Type of operations \\
\hline \multirow[t]{2}{*}{ March 2} & $18: 22$ & $18: 51$ & 29 & test flight near the FT \\
\hline & $18: 56$ & 19:18 & 24 & test flight near the FT \\
\hline \multirow[t]{2}{*}{ March 3} & $18: 29$ & $19: 55$ & 26 & test flight in the gully \\
\hline & 19:01 & $19: 23$ & 22 & test flight near the FT \\
\hline \multirow[t]{2}{*}{ March 5} & $18: 25$ & $18: 48$ & 22 & 6 temperature profiles near the FT \\
\hline & $18: 52$ & $19: 15$ & 23 & gully vs runway temperature profiles \\
\hline \multirow[t]{2}{*}{ March 6} & $18: 28$ & $18: 52$ & 24 & gully vs runway temperature profile \\
\hline & $18: 52$ & 19:15 & 23 & 5 temperature profiles near the FT \\
\hline \multirow[t]{2}{*}{ March 7} & $18: 29$ & $18: 53$ & 24 & gully vs runway temperatures profile \\
\hline & $19: 02$ & $19: 25$ & 23 & 6 temperature profiles near the FT \\
\hline \multirow[t]{2}{*}{ March 9} & $18: 29$ & $18: 53$ & 24 & gully vs runway temperatures profile \\
\hline & $18: 59$ & $19: 23$ & 24 & 3 temperature profiles near the FT \\
\hline \multirow[t]{2}{*}{ March 10} & $18: 39$ & $19: 04$ & 25 & 2 temperature profiles on the fjord \\
\hline & 19:10 & $19: 33$ & 23 & 1 temperature profile on the fjord \\
\hline
\end{tabular}

The second type was a manually controlled flight with a temperature profile measured in the gully close to the East end of the runway following by a profile at the edge of the runway (an example of the flight trajectory is marked in blue in Figure 6). This type of flight (gully versus runway flight) was conducted to investigate how local topography could influence the SBI.

On March 10 at the end of the campaign two measurement flights were carried out on Slidre Fjord near the ECCC WS to study the SBI over the ice covered ocean (fjord flight).

\subsubsection{Flux tower flights}

Figures 7-10 show temperature profiles measured on March 5-9 at various locations near the FT within the TS1 region. The measurements were conducted in clear sky conditions with light wind speeds not exceeding $4 \mathrm{~km} / \mathrm{h}$ for most of the time according to Eureka A meteorological station. Temperature profiles from the RS launched at 11:15 and 23:15 UTC from the ECCC WS and 19:00 UTC Eureka A temperatures are shown in Figures 7-10 for reference.

In the first flight on March 5 (18:25 - 18:48 UTC) the drone was set to follow predefined way-points twice (see Figure 7, pass 1 and 2) measuring 3 temperature profiles (profile 1/3,2/3, and 3/3) while flying from the East end of the runway towards the FT. As it can be seen from the figure the temperatures dropped below $-40^{\circ} \mathrm{C}$ and a strong SBI was measured by the drone with an inversion lapse rate of $\sim 0.3^{\circ} \mathrm{C} / \mathrm{m}$ within the $0-10 \mathrm{~m}$ layer. 
Table 2. 19:00 UTC meteorological conditions at the Eureka Aerodrome (Eureka A), the ECCC WS (Eureka C), and Zero Altitude PEARL Auxiliary Laboratory (OPAL)

\begin{tabular}{|c|c|c|c|c|c|c|c|c|}
\hline Date & Location & $\begin{array}{c}\text { Temperature } \\
\left({ }^{\circ} \mathrm{C}\right)\end{array}$ & $\begin{array}{l}\text { RH } \\
(\%)\end{array}$ & $\begin{array}{l}\text { Wind direction } \\
\qquad\left(^{\circ}\right)\end{array}$ & $\begin{array}{l}\text { Wind speed } \\
(\mathrm{km} / \mathrm{h})\end{array}$ & $\begin{array}{c}\text { Visibility } \\
(\mathrm{km})\end{array}$ & $\begin{array}{l}\text { Pressure } \\
\quad(\mathrm{kPa})\end{array}$ & Conditions \\
\hline \multirow[t]{3}{*}{ March 2} & Eureka A & -30.1 & 73 & 12 & 7 & 24.1 & 99.3 & mainly clear \\
\hline & Eureka C & -30.2 & 76 & 9 & 8 & NA & 100.32 & NA \\
\hline & OPAL & -30.3 & 67.6 & 71 & 7.6 & NA & 100.2 & NA \\
\hline \multirow[t]{3}{*}{ March 3} & Eureka A & -27.2 & 75 & 16 & 9 & 8.1 & 99.56 & snow \\
\hline & Eureka C & -27.3 & 79 & 9 & 7 & NA & 100.57 & NA \\
\hline & OPAL & -25.7 & 70.3 & 359 & 14 & NA & 100.43 & NA \\
\hline \multirow[t]{3}{*}{ March 5} & Eureka A & -41.8 & 66 & 36 & 3 & 24.1 & 101.21 & clear \\
\hline & Eureka C & -43.5 & 63 & 11 & 7 & NA & 102.37 & NA \\
\hline & OPAL & -44.2 & 65.5 & 53 & 3 & NA & 102.26 & NA \\
\hline \multirow[t]{3}{*}{ March 6} & Eureka A & -43.1 & 64 & 36 & 2 & 16.1 & 100.88 & ice crystals \\
\hline & Eureka C & -44.7 & 60 & 12 & 6 & NA & 102.03 & NA \\
\hline & OPAL & -43.8 & 63.6 & 18 & 9 & NA & 101.92 & NA \\
\hline \multirow[t]{3}{*}{ March 7} & Eureka A & -44.3 & 63 & 36 & 1 & 24.1 & 100.6 & clear \\
\hline & Eureka C & -45.9 & 60 & 9 & 3 & NA & 101.72 & NA \\
\hline & OPAL & -45.6 & 61.1 & 39 & 5 & NA & 101.61 & NA \\
\hline \multirow[t]{3}{*}{ March 9} & Eureka A & -45.3 & 62 & 12 & 4 & 24.1 & 100.6 & clear \\
\hline & Eureka C & -46.6 & 59 & 6 & 2 & NA & 101.41 & NA \\
\hline & OPAL & -46.8 & 61.7 & 47 & 4 & NA & 101.3 & NA \\
\hline \multirow[t]{3}{*}{ March 10} & Eureka A & -43.6 & 63 & 1 & 4 & 24.1 & 100.41 & mainly clear \\
\hline & Eureka C & -45.6 & 60 & 10 & 2 & NA & 101.8 & NA \\
\hline & OPAL & -45.5 & 61 & 62 & 6 & NA & 101.67 & NA \\
\hline
\end{tabular}

According to Figure 7, the readings from the top and rotor 3 RTDs are positively biased by $0.3^{\circ} \mathrm{C}$ and $1.7^{\circ} \mathrm{C}$ respectively in comparison with the readings from the pole RTD. Before the flights we conducted a laboratory test where all three RTDs were placed as close to each other as possible and aspirated with a room temperature air flow at a speed of $\sim 1 \mathrm{~m} / \mathrm{s}$ using a fan. The results showed the agreement between all three RTDs is within $0.2^{\circ} \mathrm{C}$. The rotor $3 \mathrm{RTD}$ showed higher temperature during the flights probably because the heat generated by the spinning motor warms up the air around it while the air is pushed downwards by the rotor 3 propeller and aspirates the RTD located below it. This result is in a good agreement with the findings reported by Greene et al. (2018), who studied the quality of the drone temperature measurements relative to the sensor locations on the 


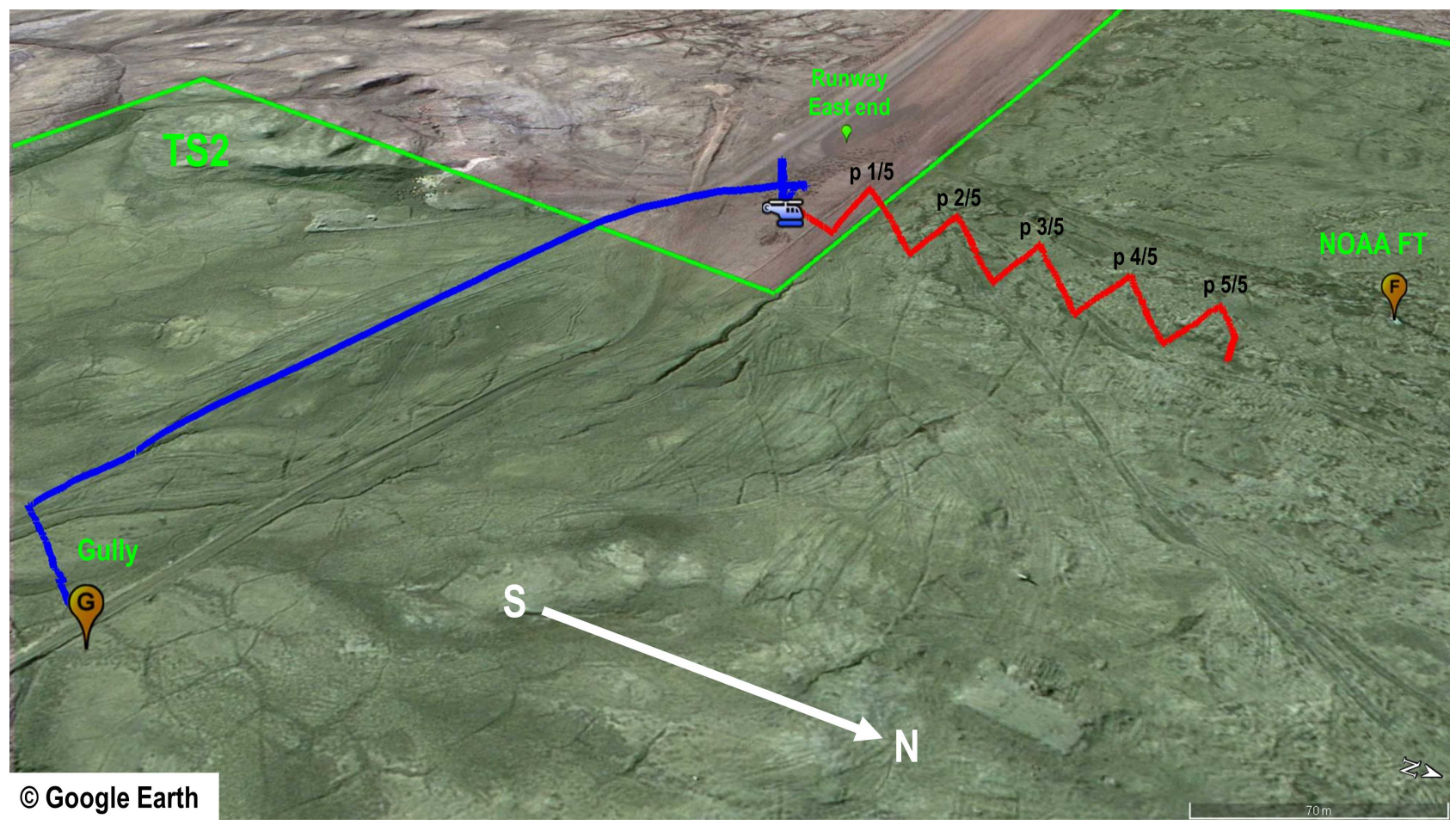

Figure 6. M210-RTK flux tower (red) and gully versus runway (blue) flight trajectories on March 6, 2020. Five vertical temperature profiles were measured during the M210-RTK flux tower flight (trajectories marked as p 1/5 - 5/5 in the figure).
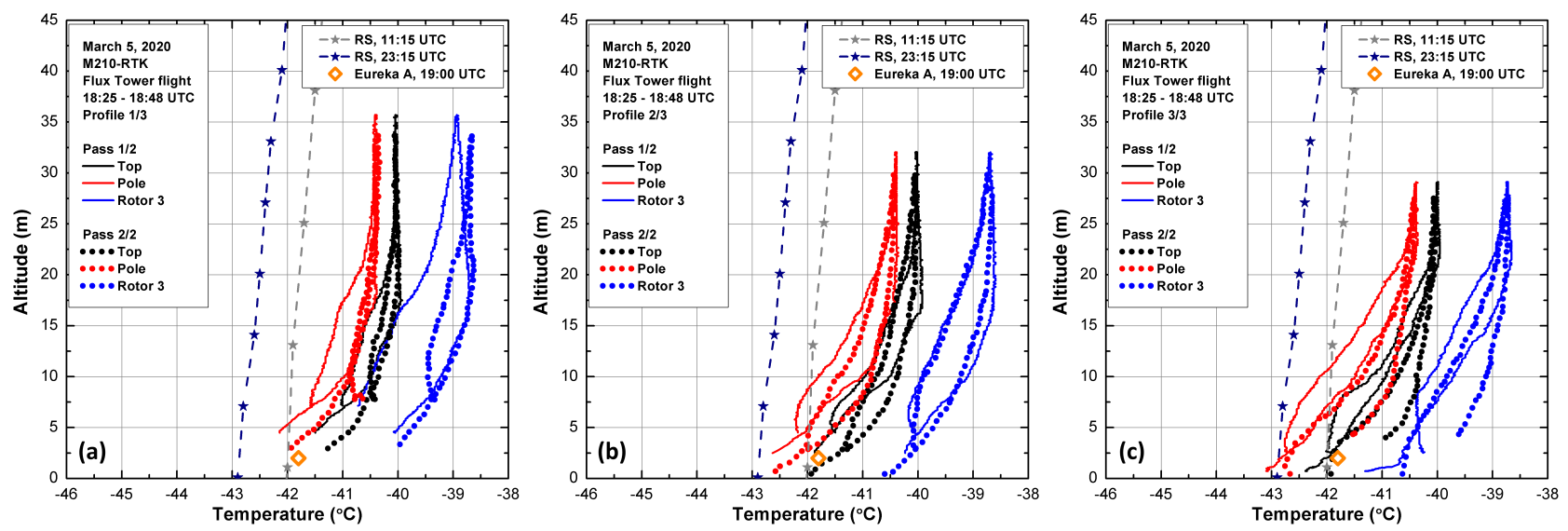

Figure 7. Vertical temperature profiles measured during 2-pass M210-RTK flux tower flight on March 6, 2020 featuring biases between RTDs attached to different locations (color coded) on the air-frame and SBI temporal and spatial variability (thin versus thick dotted lines) over the course of the flight. (a) - profile 1/3, passes 1 and 2. (b) - profile 2/3, passes 1 and 2. (c) - profile 3/3, passes 1 and 2 . 


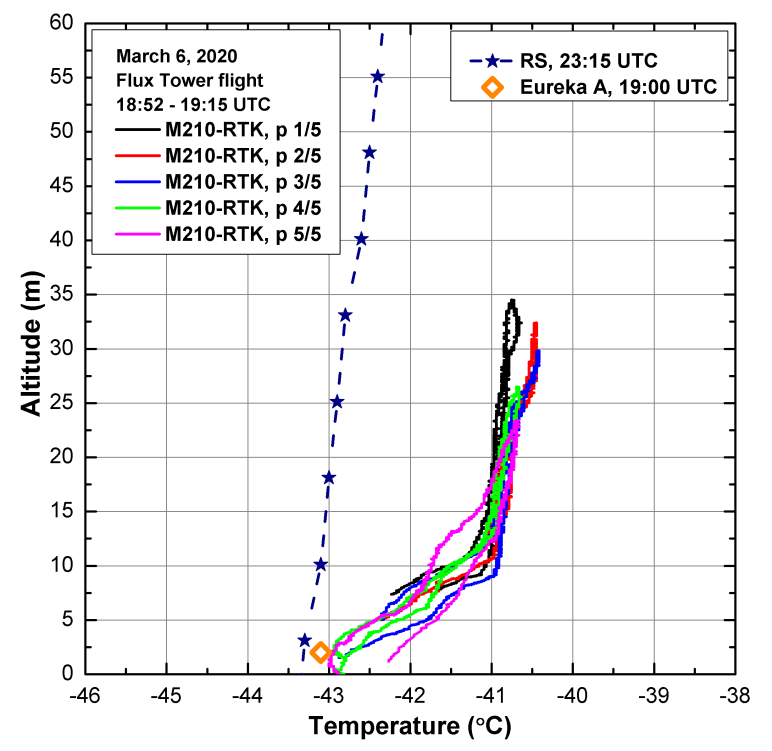

Figure 8. Vertical temperature profiles measured during single-pass M210-RTK flux tower flight on March 6, 2020. Line colors represent individual profiles (p 1/5 - 5/5) in the coarse of the flight (see Figure 6 for details).

airframe in a laboratory environment. The authors concluded the warm air streams caused by the spinning propellers can result in up to $1^{\circ} \mathrm{C}$ positive bias in the temperature readings for the sensors located in close proximity to the motors.

Some difference is also observed in the temperature measurements carried out on the drone's ascents and descents. In the isothermal region above $20 \mathrm{~m}$ the ascent/descent temperature differences are less noticeable for the top and pole sensors in comparison with the rotor 3 sensor. We associate this with the response time of the temperature sensors, vertical speed of the drone and air mixing produced by the drone propellers. The difference becomes more visible during the drone's descent into the strong SBI. The propulsion system pushes warmer air from above the drone downwards and mixing it with colder air under the drone (downwash flow). This effect is similar to one observed during the M100 test flights in 2017. Additionally, some slight variation in the readings can be observed in the profiles measured on the first and second pass conducted 27 minutes apart from each other. This is attributed to a change in the ambient conditions over time. To make the subsequent figures easier to read only the measurements from the pole RTD are presented.

On March 6 and 7, 2020 two more flights were performed (Figures 8, 9). The profiles show similar SBI pattern for both cases. As can be seen from the figures the SBI was stronger below 7-10 m with an inversion lapse rate reaching $0.2^{\circ} \mathrm{C} / \mathrm{m}$ and weaker or close to isothermal above $10 \mathrm{~m}$. For March 7 the average temperature was by about $1{ }^{\circ} \mathrm{C}$ lower along the entire altitude range in comparison with March 6 . A $\sim 1.5^{\circ} \mathrm{C}$ temperature drop was also registered by the RS. On each day between March 5 and 7 a $2-2.7^{\circ} \mathrm{C}$ positive bias in the temperatures measured by the drone at $30 \mathrm{~m}$ altitude above the ground relatively 


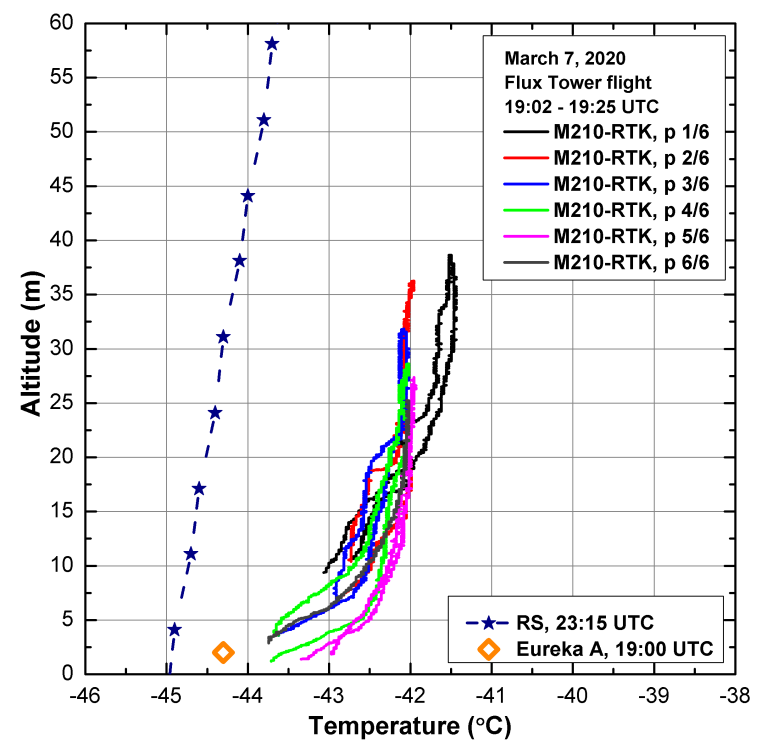

Figure 9. Temperature profiles measured during single-pass M210-RTK flux tower flight on March 7, 2020. Line colors represent individual profiles (p 1/6 - 6/6) in the coarse of the flight.

to those measured by the RS launched at 23:15 is observed. Both the drone and the RS recorded a similar inversion strength $\left(0-0.02^{\circ} \mathrm{C} / \mathrm{m}\right)$ in the altitude range higher than $30 \mathrm{~m}$ above the ground.

On March 9 the drone temperature profiles did not show as strong a SBI below $10 \mathrm{~m}$ even though the temperatures were lower and remained below $-42^{\circ} \mathrm{C}$ along the altitude range of the drone measurements (Figure 10). However, according to the RS measurements, the temperature did not change significantly in comparison with March 7 and the profiles obtained with the drone and the RS on March 9 are found to be in a good agreement featuring the inversion lapse rate of $\sim 0.03^{\circ} \mathrm{C} / \mathrm{m}$ within 5$55 \mathrm{~m}$ layer. During this flight the RTK system failed a few times and was not able maintain drone's altitude properly. Due to that the flight had to be restarted several times. The drone managed to complete the measurements of only three vertical temperature profiles and performed only one ascent/decent which covered below $10 \mathrm{~m}$ altitude range before the battery drained.

Most of the drone temperature profiles measured between March 5 and 9 show positive bias in comparison with the RS profiles (see Figures 7-11). Again, we attribute the bias to the horizontal separation between RS launch site and TS1 region and to the time difference between the drone flights and RS launches and, since drone temperature profiles agree well with 19:00 UTC Eureka A temperatures.

\subsubsection{Gully versus runway flights}

Figures 11-12 demonstrate the runway and gully temperature measurements conducted on March 5-9. The gully's lowest point was located $\sim 30 \mathrm{~m}$ below the surface level of the runway. Preliminary flights showed that due to large altitude span and limited 


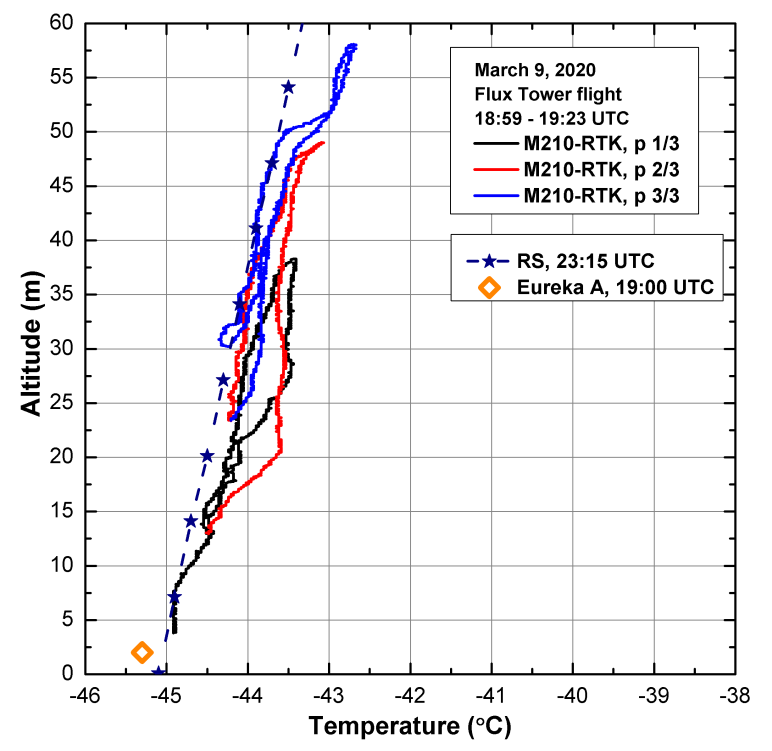

Figure 10. Temperature profiles measured during single-pass M210-RTK flux tower flight on March 9, 2020. Line colors represent individual profiles (p 1/3 - 3/3) in the coarse of the flight.

flight time it is not possible to complete ascent/descent profiles in both the gully and above the runway at low vertical speed on one set of batteries. Also to keep better track of the remaining capacity of the batteries and to maintain vertical speed at constant value it was more convenient to conduct the measurements on the ascents starting from the ground, rather than on the descents starting from some altitude level. Because of that the temperatures shown in Figures 11-12 are those obtained on the drone's ascents only. Ascent speed was kept at $0.1 \mathrm{~m} / \mathrm{s}$ or below.

On March 5 and 9 (Figure 11) the profiles measured at the runway smoothly extends the profiles measured in the gully. For both days the runway and gully profiles are close to each other in the 0-50 m region. However, for March 5 the SBI was stronger in the gully (inversion lapse rates $\sim 0.1^{\circ} \mathrm{C} / \mathrm{m}$ ), but weaker above the runway. For March 9 the shapes of the SBI at the runway and in the gully are similar to each other, while it was generally by $2^{\circ} \mathrm{C}$ colder at the gully surface in comparison with the runway surface suggesting that colder air pools in the gully depressions.

On March 6 and 7 (Figure 12) a different SBI regime was observed. The profiles are close to each other in shape but shifted vertically by an amount equal to the gully depth. This suggest the local radiative cooling was responsible for both profiles and that there was no air flow interaction between the gully and runway sites. In contrast on March 5 and 9 (Figure 11) it appears that a weak surface horizontal air flow advected from the runway to the the gully creating the similar temperature profiles. 


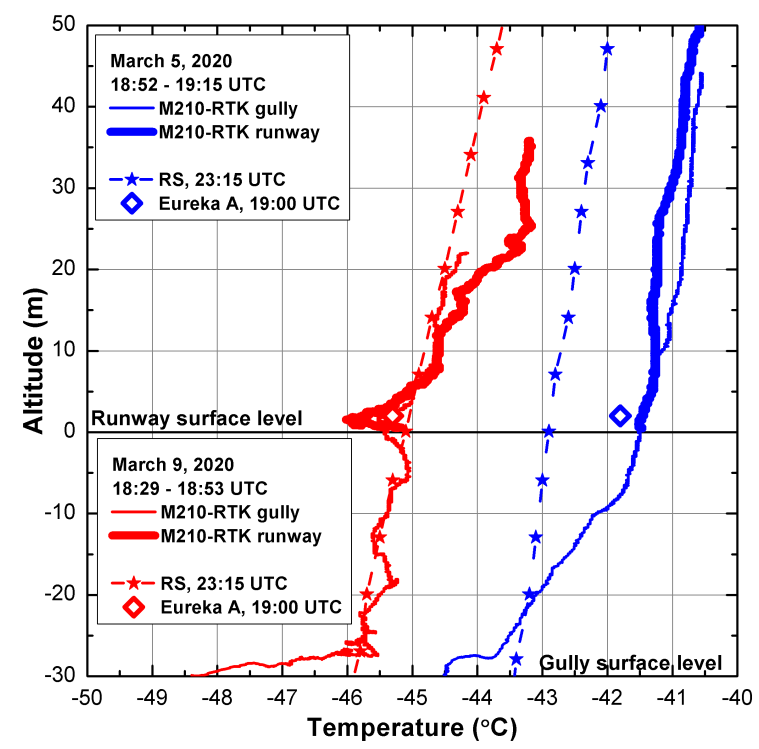

Figure 11. Temperature profiles measured during M210-RTK gully versus runway flights on March 5 and 9, 2020 featuring different shapes of SBI formed in the gully and above the runway.

\subsubsection{Fjord flights}

Figure 13 shows temperature profiles measured on March 10 on Slidre Fjord at various distances from the shoreline. The measurements were carried out to investigate the features of the temperature profiles above the ice covered ocean caused by heat flux through the sea ice (Pavelsky et al., 2011). According to the ice survey conducted on March 6 by the staff at the ECCC WS, the ice thickness was $\sim 1.9 \mathrm{~m}$. All three profiles measured at $\sim 35,210$ and $414 \mathrm{~m}$ from the shoreline feature an isothermal atmospheric layer between 10 and 30-40 m. Above $40 \mathrm{~m}$ the SBI is characterized by $\sim 0.05^{\circ} \mathrm{C} / \mathrm{m}$ inversion lapse rate, while in the region between 0 to $10 \mathrm{~m}$ above the ice surface an unstable lapse rate $\left(-0.1^{\circ} \mathrm{C} / \mathrm{m}\right) \mathrm{can}$ be seen. In this case drone measurements were conducted within $500 \mathrm{~m}$ from the RS launch site and Eureka C meteorological station. Elevation separation between the sea ice level and ground level of the RS launch site and Eureka C was $\sim 10 \mathrm{~m}$. Drone temperature profiles measured $\sim 35$ and $414 \mathrm{~m}$ from the shoreline are found to be in a good agreement with 23:15 UTC RS profile in the altitude range between 30 and $55 \mathrm{~m}$ above the sea ice and with 19:00 UTC Eureka C temperature.

\subsubsection{Lessons learned and future prospects}

Although our sensors and data collection system allowed measurements at low temperatures, the response time of our RTDs did affect the temperature readings. The use of fine wire type RTDs would be beneficial since they have faster response (Wildmann et al., 2013), however their readings could suffer from temperature fluctuations due to turbulent flows caused by spinning 
https://doi.org/10.5194/amt-2020-515

Preprint. Discussion started: 18 February 2021

(c) Author(s) 2021. CC BY 4.0 License.

(c) (i)

\section{Atmospheric Measurement \\ Techniques}

Discussions

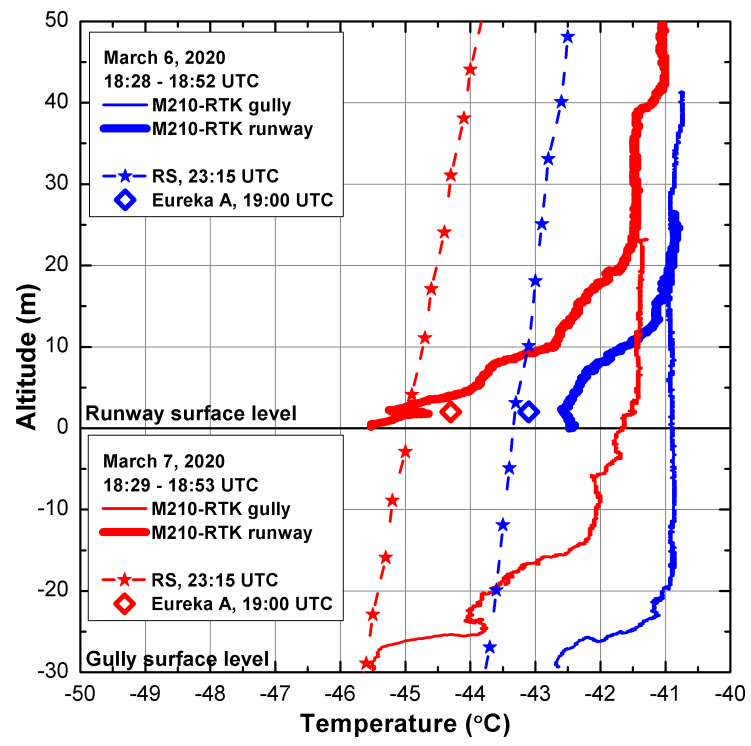

Figure 12. Temperature profiles measured during M210-RTK gully versus runway flights on March 6 and 7, 2020 featuring similar shapes of SBI formed in the gully and above the runway.

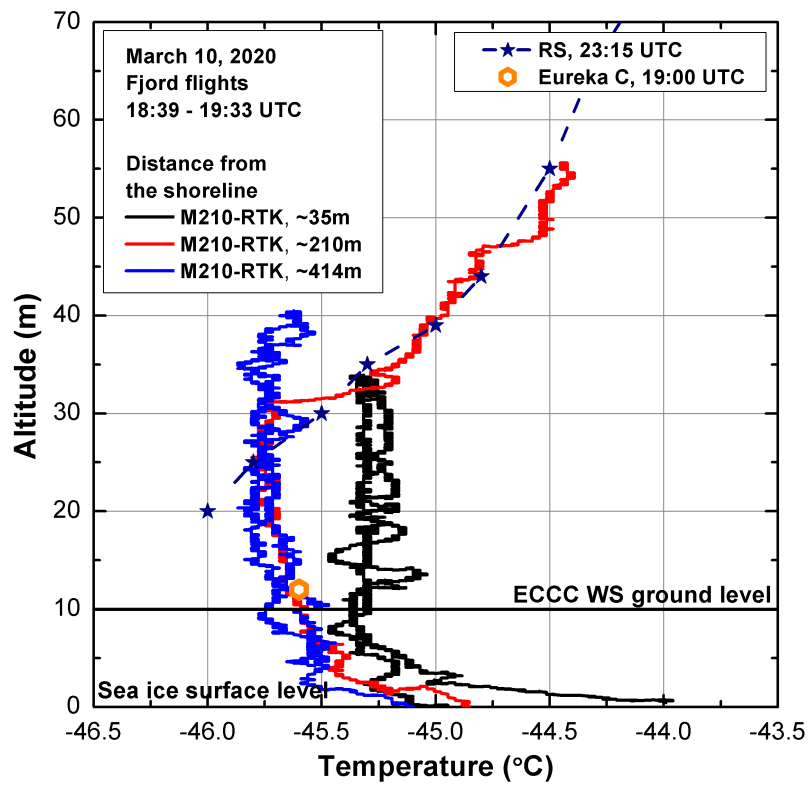

Figure 13. Temperature profiles measured during M210-RTK fjord flight on March 10, 2020 featuring the SBI over the ice covered ocean. 
propellers and would require additional filtering of raw data (Greene et al., 2018; Lampert et al., 2020a). Furthermore, we found that special care has to be taken to the temperature sensor mounting since the mechanical vibrations induced in the drone's air-frame during the flight tends to break the leads of our RTD elements.

Conducting the flight operations while residing inside a truck parked near by the flight region worked well for the pilot in control. We will continue this practice further during our winter filed operations in Eureka.

In the future, our payload can be improved by an installation of a non-contact infrared thermometer and a lidar looking downwards. The thermometer would allow measurements of the surface skin temperature simultaneously with the air temperature, while the lidar would provide data on the drone's altitude above the ground with a precision better than barometric altimeter. The lidar also can be used to track fine scale topography of the surface during the flight.

Our results show the drone's flight time per a single battery charge was within the value specified by the manufacturer. However, as we would expect, the number of available batteries, their power capacity and time required for recharging became the key factors limiting our airborne time, hence the amount of temperature measurements conducted per day. This can be solved by establishing a larger bank of spare batteries and utilization of multiple or more advanced chargers.

\section{Conclusions}

We have reported on the application of two commercial drones made by DJI to investigate the SBI within $60 \mathrm{~m}$ of the ground in the harsh environment of High Arctic winter. The results of test flights conducted with M100 drone revealed issues in its navigation system, which made autonomous flights in Eureka almost impossible. The issues were related to frequent losses of GNSS lock as well as poor performance of compass and barometric altimeter in high latitudes and at low temperatures. The M210-RTK drone equipped with RTK navigation system performed better than M100 and allowed autonomous flights when RTK mode was engaged. When M210-RTK failed to engage RTK mode it behaved similarly to M100.

Our results show that multi-rotor drones can be effectively used in the High Arctic to characterize SBI and its temporal and spatial features. Our drone temperature profiles are in agreement with the temperatures from the FT measured at 2, 6, and $10 \mathrm{~m}$ above surface and Eureka A temperature. The inversion lapse rates within the 0-10 m layer can reach the values of $\sim 0.1-$ $0.3^{\circ} \mathrm{C} / \mathrm{m}\left(\sim 100-300^{\circ} \mathrm{C} / \mathrm{km}\right)$. This is about half the lapse rate measured by Hudson and Brandt (2005) for 0-2 $\mathrm{m}$ altitude layer above the snow surface on the Antarctic Plateau. In the 10-60 m layer above the ground the SBI is characterized by weaker inversion lapse rates, which are in the range of $\sim 0.02-0.04^{\circ} \mathrm{C} / \mathrm{m}\left(\sim 20-40^{\circ} \mathrm{C} / \mathrm{km}\right)$ or less. In this region our findings agree well with the Eureka RS data.

Comparisons of the results of the SBI measurements conducted in the gully and above flat area near the East end of the runway suggesting that local topography and a change in the micro-meteorological conditions could be factors shaping the inversion in the gully. Above the sea ice, the temperature profiles are found to be isothermal above a shallow unstable surface layer revealing the impact of sensible heat flux through the ice. A detailed study with thorough analysis of the FT and drone temperature data as well as heat flux data are required for better understanding of processes responsible for the inversion formation above the ground and sea ice surface. 
Drone field studies of SBIs have the advantage of providing a rapid three-dimensional picture of the air temperature distribution. This allows one to identify changes in the inversion strength with altitude that cannot be captured neither by a fixed height flux tower nor by radiosondes, which lack sufficient vertical and time resolution. Furthermore, drones are able to study the influence of topography on the SBI structure and to measure extremely cold temperatures of air that can pool in topographic depressions. Finally we demonstrated that drone measurements can determine the depth of unstable surface layers that form over sea ice during calm and clear conditions. All these unique capabilities by a drone can provide boundary layer meteorologists with a more realistic assessment of the processes that shape the temperature distribution in winter Arctic environments with important implications in the interpretation of regional variations in the skin-surface air temperature difference and the surface sensible and radiative heat fluxes.

Data availability. All the measurement data are available from ABT upon request.

Author contributions. ABT designed the study, developed the payload, conducted the measurement campaigns, and performed data quality control and analysis. GL designed the study and was a mentor of the NOAA FT. JRD was the Principal Investigator for the PEARL and facilitated the success of the project. All authors contributed to and commented on the paper.

Acknowledgements. The authors would like to acknowledge the following groups and individuals for their technical support during field campaigns in Eureka: Canadian Arctic ACE/OSIRIS Validation Campaign project lead K. Walker, PEARL site manager P. Fogal, PEARL PI K. Strong, CANDAC/PAHA operators: A. Hall, J. Gallagher, M. Maurice, and P. McGovern; CANDAC/PAHA data manager Y. Tsehtik. Authors also thank the Eureka Weather Station staff for operation support. The authors acknowledge T. Uttal (NOAA) for continuous support and operation of the flux tower in Eureka and for providing valuable data from it. ABT thanks M. Sauerberg (AerialTech) for providing training on M210-RTK drone and J. Allen (Monitoring/Data Services, ECCC) for providing details on Eureka meteorological and radiosonde data sets. ABT acknowledges A. Kräuchi, R. Philipona and K. Bärfuss for sharing their experience and fruitful conversations on the drones and their payloads. The authors thank E. McCullough for critically reading of the manuscript and valuable comments.

PEARL research is supported by: the Canadian Foundation for Innovation; the Ontario Innovation Trust; the Ontario Ministry of Research and Innovation; the Nova Scotia Research and Innovation Trust; the Natural Sciences and Engineering Research Council (NSERC); the Canadian Foundation for Climate and Atmospheric Science; ECCC; Polar Continental Shelf Project; the Department of Indigenous and Northern Affairs Canada; and the Canadian Space Agency (CSA). This work was carried out at PEARL partially during 2017-2020 Canadian Arctic ACE/OSIRIS Validation Campaigns, which were funded by: CSA, ECCC, NSERC, and the Northern Scientific Training Program. 


\section{References}

Ader, M. and Axelsson, D.: Drones in arctic environments, Master's thesis, KTH Royal Institute of Technology, Stockholm, Sweden, 2017.

Adolph, A. C., Albert, M. R., and Hall, D. K.: Near-surface temperature inversion during summer at Summit, Greenland, and its relation to MODIS-derived surface temperatures, The Cryosphere, 12, 907-920, https://doi.org/10.5194/tc-12-907-2018, https://tc.copernicus.org/ articles/12/907/2018/, 2018.

Bernard-Grand'Maison, C. and Pollard, W.: An estimate of ice wedge volume for a High Arctic polar desert environment, Fosheim Peninsula, Ellesmere Island, The Cryosphere, 12, 3589-3604, https://doi.org/10.5194/tc-12-3589-2018, https://tc.copernicus.org/articles/12/3589/ 2018/, 2018.

Bosch Sensortec: BMP280 Digital Pressure Sensor, https://www.bosch-sensortec.com/media/boschsensortec/downloads/datasheets/ bst-bmp280-ds001.pdf, 2018.

Bradley, R. S., Keimig, F. T., and Diaz, H. F.: Recent changes in the North American Arctic boundary layer in winter, Journal of Geophysical Research: Atmospheres, 98, 8851-8858, https://doi.org/10.1029/93JD00311, https://agupubs.onlinelibrary.wiley.com/doi/abs/10. 1029/93JD00311, 1993.

Bärfuss, K., Pätzold, F., Altstädter, B., Kathe, E., Nowak, S., Bretschneider, L., Bestmann, U., and Lampert, A.: New Setup of the UAS ALADINA for Measuring Boundary Layer Properties, Atmospheric Particles and Solar Radiation, Atmosphere, 9, 28, https://doi.org/10.3390/atmos9010028, http://dx.doi.org/10.3390/atmos9010028, 2018.

Burgués, J. and Marco, S.: Environmental chemical sensing using small drones: A review, Science of The Total Environment, 748, 141 172, https://doi.org/https://doi.org/10.1016/j.scitotenv.2020.141172, http://www.sciencedirect.com/science/article/pii/ S004896972034701X, 2020.

Cassano, J. J., Seefeldt, M. W., Palo, S., Knuth, S. L., Bradley, A. C., Herrman, P. D., Kernebone, P. A., and Logan, N. J.: Observations of the atmosphere and surface state over Terra Nova Bay, Antarctica, using unmanned aerial systems, Earth System Science Data, 8, 115-126, https://doi.org/10.5194/essd-8-115-2016, https://essd.copernicus.org/articles/8/115/2016/, 2016.

Chabot, D. and Bird, D. M.: Wildlife research and management methods in the 21 st century: Where do unmanned aircraft fit in?, Journal of Unmanned Vehicle Systems, 3, 137-155, https://doi.org/10.1139/juvs-2015-0021, https://doi.org/10.1139/juvs-2015-0021, 2015.

Cowley, D., Moriarty, C., Geddes, G., Brown, G., Wade, T., and Nichol, C.: UAVs in Context: Archaeological Airborne Recording in a National Body of Survey and Record, Drones, 2, 2, https://doi.org/10.3390/drones2010002, http://dx.doi.org/10.3390/drones2010002, 2017.

DJI: https://www.dji.com/ca/matrice100, last visited 2020-08-10, a.

DJI: https://www.dji.com/ca/matrice-200-series, last visited 2020-08-10, b.

Dodd, E. M. A., Veal, K. L., Ghent, D. J., van den Broeke, M. R., and Remedios, J. J.: Toward a Combined Surface Temperature Data Set for the Arctic From the Along-Track Scanning Radiometers, Journal of Geophysical Research: Atmospheres, 124, 6718-6736, https://doi.org/10.1029/2019JD030262, https://agupubs.onlinelibrary.wiley.com/doi/abs/10.1029/2019JD030262, 2019.

Ebeid, E., Skriver, M., and Jin, J.: A Survey on Open-Source Flight Control Platforms of Unmanned Aerial Vehicle, in: 2017 Euromicro Conference on Digital System Design (DSD), pp. 396-402, https://doi.org/10.1109/DSD.2017.30, 2017.

Fogal, P., LeBlanc, L., and Drummond, J.: The Polar Environment Atmospheric Research Laboratory (PEARL): Sounding the Atmosphere at $80^{\circ}$ North, ARCTIC, 66, 377-386, https://doi.org/10.14430/arctic4321, https://arctic.journalhosting.ucalgary.ca/arctic/index.php/arctic/ article/view/4321, 2013. 
https://doi.org/10.5194/amt-2020-515

Preprint. Discussion started: 18 February 2021

(c) Author(s) 2021. CC BY 4.0 License.
Atmospheric

Measurement

Techniques

Discussions

Gaffey, C. and Bhardwaj, A.: Applications of Unmanned Aerial Vehicles in Cryosphere: Latest Advances and Prospects, Remote Sensing, 12, 948, https://doi.org/10.3390/rs12060948, http://dx.doi.org/10.3390/rs12060948, 2020.

Grachev, A. A., Persson, P. O. G., Uttal, T., Akish, E. A., Cox, C. J., Morris, S. M., Fairall, C. W., Stone, R. S., Lesins, G., Makshtas, A. P., and Repina, I. A.: Seasonal and latitudinal variations of surface fluxes at two Arctic terrestrial sites, Climate Dynamics, 51, 1793-1818, https://doi.org/10.1007/s00382-017-3983-4, https://doi.org/10.1007/s00382-017-3983-4, 2018.

Greene, B. R., Segales, A. R., Waugh, S., Duthoit, S., and Chilson, P. B.: Considerations for temperature sensor placement on rotary-wing unmanned aircraft systems, Atmospheric Measurement Techniques, 11, 5519-5530, https://doi.org/10.5194/amt-11-5519-2018, https: //amt.copernicus.org/articles/11/5519/2018/, 2018.

Gustafsson, T. and Bendz, E.: D8.5 - Guidelines for drone usage in arctic environment, Tech. Rep. 730938-INTERACT, Integrating Activities for Advanced Communities, https://eu-interact.org/app/uploads/2018/09/D8.5.pdf, 2018.

Hudson, S. R. and Brandt, R. E.: A Look at the Surface-Based Temperature Inversion on the Antarctic Plateau, Journal of Climate, 18, 1673-1696, https://doi.org/10.1175/JCLI3360.1, https://doi.org/10.1175/JCLI3360.1, 2005.

Jouvet, G., Weidmann, Y., van Dongen, E., Lüthi, M. P., Vieli, A., and Ryan, J. C.: High-Endurance UAV for Monitoring Calving Glaciers: Application to the Inglefield Bredning and Eqip Sermia, Greenland, Frontiers in Earth Science, 7, 206, https://doi.org/10.3389/feart.2019.00206, https://www.frontiersin.org/article/10.3389/feart.2019.00206, 2019.

Key, J., Wang, X., Liu, Y., Dworak, R., and Letterly, A.: The AVHRR Polar Pathfinder Climate Data Records, Remote Sensing, 8, 167, https://doi.org/10.3390/rs8030167, http://dx.doi.org/10.3390/rs8030167, 2016.

Knuth, S. L. and Cassano, J. J.: Estimating Sensible and Latent Heat Fluxes Using the Integral Method from in situ Aircraft Measurements, Journal of Atmospheric and Oceanic Technology, 31, 1964-1981, https://doi.org/10.1175/JTECH-D-14-00008.1, https://doi.org/10.1175/ JTECH-D-14-00008.1, 2014.

Kramar, V. and Maatta, H.: UAV Arctic Challenges and the First Step: Printed Temperature Sensor, in: Proceedings of the 23rd Conference of Open Innovations Association FRUCT, FRUCT’23, FRUCT Oy, Helsinki, Uusimaa, FIN, 2018.

Kräuchi, A. and Philipona, R.: Return glider radiosonde for in situ upper-air research measurements, Atmospheric Measurement Techniques, 9, 2535-2544, https://doi.org/10.5194/amt-9-2535-2016, https://amt.copernicus.org/articles/9/2535/2016/, 2016

Lampert, A., Altstädter, B., Bärfuss, K., Bretschneider, L., Sandgaard, J., Michaelis, J., Lobitz, L., Asmussen, M., Damm, E., Käthner, R., Krüger, T., Lüpkes, C., Nowak, S., Peuker, A., Rausch, T., Reiser, F., Scholtz, A., Sotomayor Zakharov, D., Gaus, D., Bansmer, S., and Wehner, Birgit; Pätzold, F.: Unmanned Aerial Systems for Investigating the Polar Atmospheric Boundary Layer-Technical Challenges and Examples of Applications, Atmosphere, 11, 416, https://doi.org/10.3390/atmos11040416, http://dx.doi.org/10.3390/atmos11040416, 2020a.

Lampert, A., Pätzold, F., Asmussen, M. O., Lobitz, L., Krüger, T., Rausch, T., Sachs, T., Wille, C., Sotomayor Zakharov, D., Gaus, D., Bansmer, S., and Damm, E.: Studying boundary layer methane isotopy and vertical mixing processes at a rewetted peatland site using an unmanned aircraft system, Atmospheric Measurement Techniques, 13, 1937-1952, https://doi.org/10.5194/amt-13-1937-2020, https: //amt.copernicus.org/articles/13/1937/2020/, 2020b.

540 Lesins, G., Duck, T. J., and Drummond, J. R.: Climate trends at Eureka in the Canadian high arctic, Atmosphere-Ocean, 48, 59-80, https://doi.org/10.3137/AO1103.2010, https://doi.org/10.3137/AO1103.2010, 2010.

Lesins, G., Duck, T. J., and Drummond, J. R.: Surface Energy Balance Framework for Arctic Amplification of Climate Change, Journal of Climate, 25, 8277-8288, https://doi.org/10.1175/JCLI-D-11-00711.1, https://doi.org/10.1175/JCLI-D-11-00711.1, 2012. 
https://doi.org/10.5194/amt-2020-515

Preprint. Discussion started: 18 February 2021

(c) Author(s) 2021. CC BY 4.0 License.
Atmospheric

Measurement

Techniques

Discussions

Li, Z.-L., Tang, B.-H., Wu, H., Ren, H., Yan, G., Wan, Z., Trigo, I. F., and Sobrino, J. A.: Satellite-derived land surface temperature: Current status and perspectives, Remote Sensing of Environment, 131, 14 - 37, https://doi.org/https://doi.org/10.1016/j.rse.2012.12.008, http://www.sciencedirect.com/science/article/pii/S0034425712004749, 2013.

Mašić, A., Bibić, D., Pikula, B. D., Džaferović-Mašić, E., and Musemić, R.: Experimental study of temperature inversions above urban area using unmanned aerial vehicle, Thermal Science, 23, 3327-3338, http://ezproxy.library.dal.ca/login?url=https://www.proquest.com/ docview/2429071123? accountid=10406, copyright - (C) 2019. This work is licensed under https://creativecommons.org/licenses/by-ncnd/4.0/ (the "License"). Notwithstanding the ProQuest Terms and Conditions, you may use this content in accordance with the terms of the License; Last updated - 2020-07-31, 2019.

Maxim Integrated Products, Inc.: MAX31865PMB1 Peripheral Module, https://datasheets.maximintegrated.com/en/ds/MAX31865PMB1. pdf, 2014.

Omega Engineering, Inc.: Ceramic Wire-Wound Platinum RTD Elements, https://assets.omega.com/spec/1PT100K-RTD-ELEMENTS.pdf.

Pavelsky, T. M., Boé, J., Hall, A., and Fetzer, E. J.: Atmospheric inversion strength over polar oceans in winter regulated by sea ice, Climate Dynamics, 36, 945-955, https://doi.org/10.1007/s00382-010-0756-8, https://doi.org/10.1007/s00382-010-0756-8, 2011.

Pesaran, A., Santhanagopalan, S., and Kim, G. H.: Addressing the Impact of Temperature Extremes on Large Format Li-Ion Batteries for Vehicle Applications, in: Presented at the 30th International Battery Seminar, 11-14 March 2013, Ft. Lauderdale, Florida; Related Information: NREL (National Renewable Energy Laboratory), 2013.

Pollard, W. H.: Distribution and characterization of ground ice on Fosheim Peninsula, Ellesmere Island, Nunavut., in: Environmental response to climate change in the Canadian High Arctic: geological survey of Canada. Bulletin 529, Garneau M., Alt B.T. (eds), p. 207-233, 2000.

Roldán, J., Joossen, G., Sanz, D., del Cerro, J., and Barrientos, A.: Mini-UAV Based Sensory System for Measuring Environmental Variables in Greenhouses, Sensors, 15, 3334-3350, https://doi.org/10.3390/s150203334, http://dx.doi.org/10.3390/s150203334, 2015.

Shahmoradi, J., Talebi, E., Roghanchi, P., and Hassanalian, M.: A Comprehensive Review of Applications of Drone Technology in the Mining Industry, Drones, 4, 34, https://doi.org/10.3390/drones4030034, http://dx.doi.org/10.3390/drones4030034, 2020.

Smith, S. L. and Bonnaventure, P. P.: Quantifying Surface Temperature Inversions and Their Impact on the Ground Thermal Regime at a High Arctic Site, Arctic, Antarctic, and Alpine Research, 49, 173-185, https://doi.org/10.1657/AAAR0016-039, https://doi.org/10.1657/ AAAR0016-039, 2017.

Soliman, A., Duguay, C., Saunders, W., and Hachem, S.: Pan-Arctic Land Surface Temperature from MODIS and AATSR: Product Development and Intercomparison, Remote Sensing, 4, 3833-3856, https://doi.org/10.3390/rs4123833, http://dx.doi.org/10.3390/rs4123833, 2012.

Taalas, P.: Guide to Instruments and Methods of Observation (WMO-No. 8), vol. Volume I - Measurement of Meteorological Variables, https://library.wmo.int/doc_num.php?explnum_id=10179, 2018.

The Raspberry Pi Foundation: https://www.raspberrypi.org/, last visited 2021-02-17.

575 Villa, T., Salimi, F., Morton, K., Morawska, L., and Gonzalez, F.: Development and Validation of a UAV Based System for Air Pollution Measurements, Sensors, 16, 2202, https://doi.org/10.3390/s16122202, http://dx.doi.org/10.3390/s16122202, 2016.

Walden, V. P., Mahesh, A., and Warren, S. G.: Comment on "Recent changes in the North American Arctic boundary layer in winter" by R. S. Bradley et al., Journal of Geophysical Research: Atmospheres, 101, 7127-7134, https://doi.org/10.1029/95JD03233, https://agupubs. onlinelibrary.wiley.com/doi/abs/10.1029/95JD03233, 1996. 
https://doi.org/10.5194/amt-2020-515

Preprint. Discussion started: 18 February 2021

(C) Author(s) 2021. CC BY 4.0 License.

(c) (1)

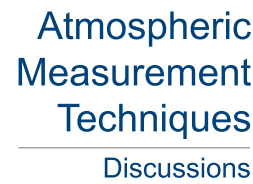

580 Wildmann, N., Mauz, M., and Bange, J.: Two fast temperature sensors for probing of the atmospheric boundary layer using small remotely piloted aircraft (RPA), Atmospheric Measurement Techniques, 6, 2101-2113, https://doi.org/10.5194/amt-6-2101-2013, https: //amt.copernicus.org/articles/6/2101/2013/, 2013.

Zappa, C. J., Brown, S. M., Laxague, N. J. M., Dhakal, T., Harris, R. A., Farber, A. M., and Subramaniam, A.: Using Ship-Deployed HighEndurance Unmanned Aerial Vehicles for the Study of Ocean Surface and Atmospheric Boundary Layer Processes, Frontiers in Marine Science, 6, 777, https://doi.org/10.3389/fmars.2019.00777, https://www.frontiersin.org/article/10.3389/fmars.2019.00777, 2020.

Zhang, S., Xu, K., and Jow, T.: The low temperature performance of Li-ion batteries, Journal of Power Sources, 115 , 137 - 140, https://doi.org/https://doi.org/10.1016/S0378-7753(02)00618-3, http://www.sciencedirect.com/science/article/pii/S0378775302006183, 2003.

Zhang, Y., Seidel, D. J., Golaz, J.-C., Deser, C., and Tomas, R. A.: Climatological Characteristics of Arctic and Antarctic Surface-Based Inversions*, Journal of Climate, 24, 5167-5186, https://doi.org/10.1175/2011JCLI4004.1, https://doi.org/10.1175/2011JCLI4004.1, 2011.

Zubax Robotics: Zubax GNSS 2 Datasheet, https://files.zubax.com/products/com.zubax.gnss/Zubax_GNSS_2_Datasheet.pdf, 2019. 